Check for updates

Cite this: J. Mater. Chem. A, 2019, 7, 9368

Received 29th October 2018

Accepted 18th December 2018

DOI: $10.1039 / \mathrm{c} 8 \mathrm{ta10410g}$

rsc.li/materials-a

\section{A review of nanostructured non-titania photocatalysts and hole scavenging agents for $\mathrm{CO}_{2}$ photoreduction processes}

\author{
Jeannie Z. Y. Tan (D) and M. Mercedes Maroto-Valer
}

\section{Introduction}

Fossil fuels are currently unrivalled for energy generation, and our existing infrastructure is built to handle fossil fuels for transportation, heating and electricity. ${ }^{1}$ Our heavy reliance on fossil fuels results in annual emissions of $32 \mathrm{Gt}$ of $\mathrm{CO}_{2} .{ }^{2}$ This is likely to increase to $36-43$ Gt by 2035 , subject to policies governing $\mathrm{CO}_{2}$ emissions and energy use, even with increasing renewable energy sources. ${ }^{3}$ To mitigate these environmental issues as well as alleviate our dependence on fossil fuels, harvesting the seemingly infinite solar energy and storing it in the form of chemical fuels hold significant promise to address current and future energy demands. Moreover, the chemical industry and a vast amount of chemical products rely heavily on using fossil fuel feedstock. This further motivates the development of sustainable processes to generate fuels and chemical feedstock from water and $\mathrm{CO}_{2}$ using solar energy. Such a process is akin to photosynthesis in nature, and therefore, it is referred to as the artificial photosynthesis.

Photoelectrocatalytic reduction of $\mathrm{CO}_{2}$ in aqueous suspensions using semiconducting powders was first proposed by Inoue et al. in 1979. ${ }^{4}$ Later in 1987, the photocatalytic reduction of $\mathrm{CO}_{2}$ to $\mathrm{CH}_{4}$ in the presence of $\mathrm{H}_{2} \mathrm{O}$ was proposed by Thampi et $a .^{5}$ Since then, an increasing number of studies on the photo(electro)catalytic reduction of $\mathrm{CO}_{2}$ have been conducted (Fig. 1). Among these studies, almost $50 \%$ focused on the materials employed as photocatalysts for conversion of $\mathrm{CO}_{2}$ under UV and/or visible irradiation. The rest of the studies

Research Centre for Carbon Solutions (RCCS), Heriot-Watt University, Edinburgh EH14 4AS, UK.E-mail:j.tan@hw.ac.uk concentrated mainly on modelling or process development. The use of $\mathrm{TiO}_{2}$ as a photocatalyst for $\mathrm{CO}_{2}$ reduction has been extensively studied and has been reviewed elsewhere. ${ }^{\mathbf{6 - 1 0}}$ However, the lack of systematic studies of non- $\mathrm{TiO}_{2}$ semiconducting materials, namely metal sulphides, oxides, oxynitrides and nitrides, for $\mathrm{CO}_{2}$ photoreduction $\left(\mathrm{CO}_{2} \mathrm{PR}\right)$ has inhibited the development of these photocatalysts compared to titania-based photocatalysts.

Although different photocatalysts (i.e., titania and non-titania based semiconductors) have been proposed in the literature, the overall $\mathrm{CO}_{2} \mathrm{PR}$ conversion remains low especially under sunlight irradiation, making the $\mathrm{CO}_{2} \mathrm{PR}$ system not practical for commercialisation. To further increase the efficiency of $\mathrm{CO}_{2} \mathrm{PR}$, the introduction of scavenging agents into the $\mathrm{CO}_{2} \mathrm{PR}$ system has been proposed. However, so far, the introduction of hole scavenging agents has not been systematically studied, though studies started in the last century. Therefore, the necessity to systematically scrutinise the recent development of non- $\mathrm{TiO}_{2}$ photocatalysts and hole scavenging agents for $\mathrm{CO}_{2} \mathrm{PR}$ is of great demand.

There are enormous scientific and technical challenges involved in making even the simplest fuel, $\mathrm{H}_{2}$, and even more so for carbon-based fuels by means of $\mathrm{CO}_{2}$ photoreduction. Similar to other photocatalytic processes, solar-driven photocatalytic conversion of $\mathrm{CO}_{2}$ in the presence of $\mathrm{H}_{2} \mathrm{O}$ to hydrocarbon fuels uses semiconducting materials to harvest solar energy and provides active sites to allow the photocatalytic conversion process to occur. The basic steps of the photocatalytic process can be summarised as follows:

(1) generation of charge carriers (electron-hole pairs) by semiconducting materials upon absorption of photons with appropriate energy from the irradiation of light, 
(2) separation of charge carriers and their transportation to the surface of the photocatalyst, and

(3) chemical redox reactions between the charge carriers and the reactants.

$\mathrm{CO}_{2} \mathrm{PR}$ with $\mathrm{H}_{2} \mathrm{O}$ into fuels is illustrated in Fig. 2. $\mathrm{TiO}_{2}$ was the first material used for $\mathrm{CO}_{2} \mathrm{PR},{ }^{5}$ and since then it has been widely used because of its abundance, availability, high chemical stability, low cost and non-toxicity. ${ }^{12}$ Despite the great effort made in the $\mathrm{CO}_{2} \mathrm{PR}$ using $\mathrm{TiO}_{2}$ and its derivative materials, the efficiency of the process remains low, ${ }^{7}$ mainly attributed to the following factors:

(a) Rapid recombination of photogenerated electron-hole pairs; ${ }^{10}$

(b) Mild reducing power;

- The potential of the conduction band electrons is only slightly more negative than the multi-electron reduction potentials of $\mathrm{CO}_{2}$, thus providing a very small driving force, whereas the potential of the valence band holes is much more positive than the water oxidation potential. ${ }^{7}$

(c) Limited visible light absorption due to the wide bandgap (3.0-3.2 eV) of $\mathrm{TiO}_{2} .^{\mathbf{1 3 , 1 4}}$

Strategies including doping, ${ }^{15,16}$ coupling with semiconductors, ${ }^{17-19}$ dye sensitizing, ${ }^{20,21}$ surface modification ${ }^{22,23}$ etc. have been extensively used to improve $\mathrm{TiO}_{2}$ photocatalysts and are summarised elsewhere..$^{\mathbf{9 1 4 , 2 4 , 2 5}}$ However, the two most commonly used methods for extending the absorption range to visible light, namely sensitization or doping, do not fully address the optical issue of wide bandgap materials. Sensitizing agents (e.g., dyes or quantum dots) often degrade when exposed to UV light and photogenerate oxidizing holes in $\mathrm{TiO}_{2}{ }^{7}$ Dopant atoms, on the other hand, can become the centers of charge recombination. Moreover, the additional energy states associated with foreign atoms are highly localized, resulting in suppressed charge mobility. ${ }^{27}$ Hence, while $\mathrm{TiO}_{2}$ remains a benchmark photocatalyst, there is a lot of interest in developing other materials for $\mathrm{CO}_{2} \mathrm{PR}$, such as carbon-based semiconductors (e.g., graphene-based composites, ${ }^{\mathbf{2 8 , 2 9}}$ carbon nanotube composites, ${ }^{30}$ g- $_{3} \mathrm{~N}_{4}$ based composites ${ }^{31-33}$ and

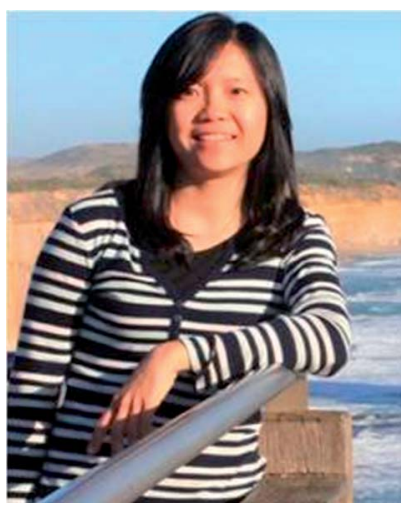

Dr Jeannie Z. Y. Tan received her BSc. (2010) from Universiti Sains Malaysia and her Msc. (2013) from Zhejiang University. She obtained her PhD (2017) from the University of Melbourne and after that joined the Research Centre for Carbon Solutions at Heriot-Watt University as a Research Associate. She is currently working on an EPSRCfunded project to develop innovative solutions for solar fuel conversion. She currently has 19 publications that have been cited over 200 times. She is also a reviewer for 2 journals (RSC Nanoscale Advances and Journal of Electronics \& Telecommunication). hybrid organic-inorganic materials ${ }^{34-37}$ ) and other inorganic transition or main group metal oxides, sulphides, oxynitrides, and nitrides. Since the use of carbon-based semiconductors for $\mathrm{CO}_{2} \mathrm{PR}$ has been reviewed elsewhere,,$^{\mathbf{3 0 , 3 4 , 3 8 , 3 9}}$ these photocatalysts are not be discussed herein.

Inorganic semiconductors, namely metal oxides, sulphides, oxynitrides and nitrides, are among the first semiconductors

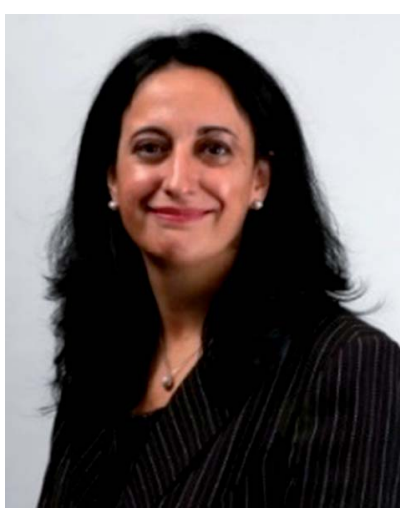

Prof M. Mercedes Maroto-Valer (FRSE, FIChemE, FRSC, and FRSA) is the Assistant Deputy Principal (Research \& Innovation) and Director of the Research Centre for Carbon Solutions (RCCS) at Heriot-Watt University. She leads a multidisciplinary team of over 50 researchers developing novel solutions to meet the worldwide demand for energy. Her team's expertise comprises energy generation, conversion and industry, carbon capture, conversion, transport and storage, emission control, low carbon fuels, and lowcarbon systems. She has over 450 publications, of which she edited 4 books, and $32 \%$ of her publications are among the top $10 \%$ most cited publications worldwide. Her research portfolio includes projects worth $\sim £ 35 \mathrm{~m}$, and she has been awarded a prestigious European Research Council (ERC) Advanced Award. She obtained a BSc with Honours (First Class) in Applied Chemistry in 1993 and then a PhD in 1997 at the University of Strathclyde (Scotland). Following a one-year postdoctoral fellowship at the Centre for Applied Energy Research (CAER) at the University of Kentucky in the US, she moved to Pennsylvania State University in the US, where she worked as a Research Fellow and from 2001 as an Assistant Professor and became the Program Coordinator for Sustainable Energy. She joined the University of Nottingham as a Reader in 2005, and within 3 years she was promoted to Professor in Energy Technologies. During her time at Nottingham she was the head of the Energy and Sustainability Research Division at the Faculty of Engineering. In 2012, she joined Heriot-Watt University as the first Robert Buchan Chair in Sustainable Energy Engineering and has served as the head of the Institute for Mechanical, Processing and Energy Engineering (School of Engineering and Physical Sciences) and the pan-University Energy Academy. She is a member of the Directorate of the Scottish Carbon Capture and Storage (SCCS). She holds leading positions in professional societies and editorial boards, and has received numerous international prizes and awards, including the 2018 Merit Award Society of Spanish Researchers in the United Kingdom (SRUK/CERU), 2013 Hong Kong University William Mong Distinguished Lecture, 2011 RSC Environment, Sustainability and Energy Division Early Career Award, 2009 Philip Leverhulme Prize, 2005 U.S. Department of Energy Award for Innovative Development, 1997 Ritchie Prize, 1996 Glenn Award-the Fuel Chemistry Division of the American Chemical Society and 1993 ICI Chemical \& Polymers Group Andersonian Centenary Prize. 


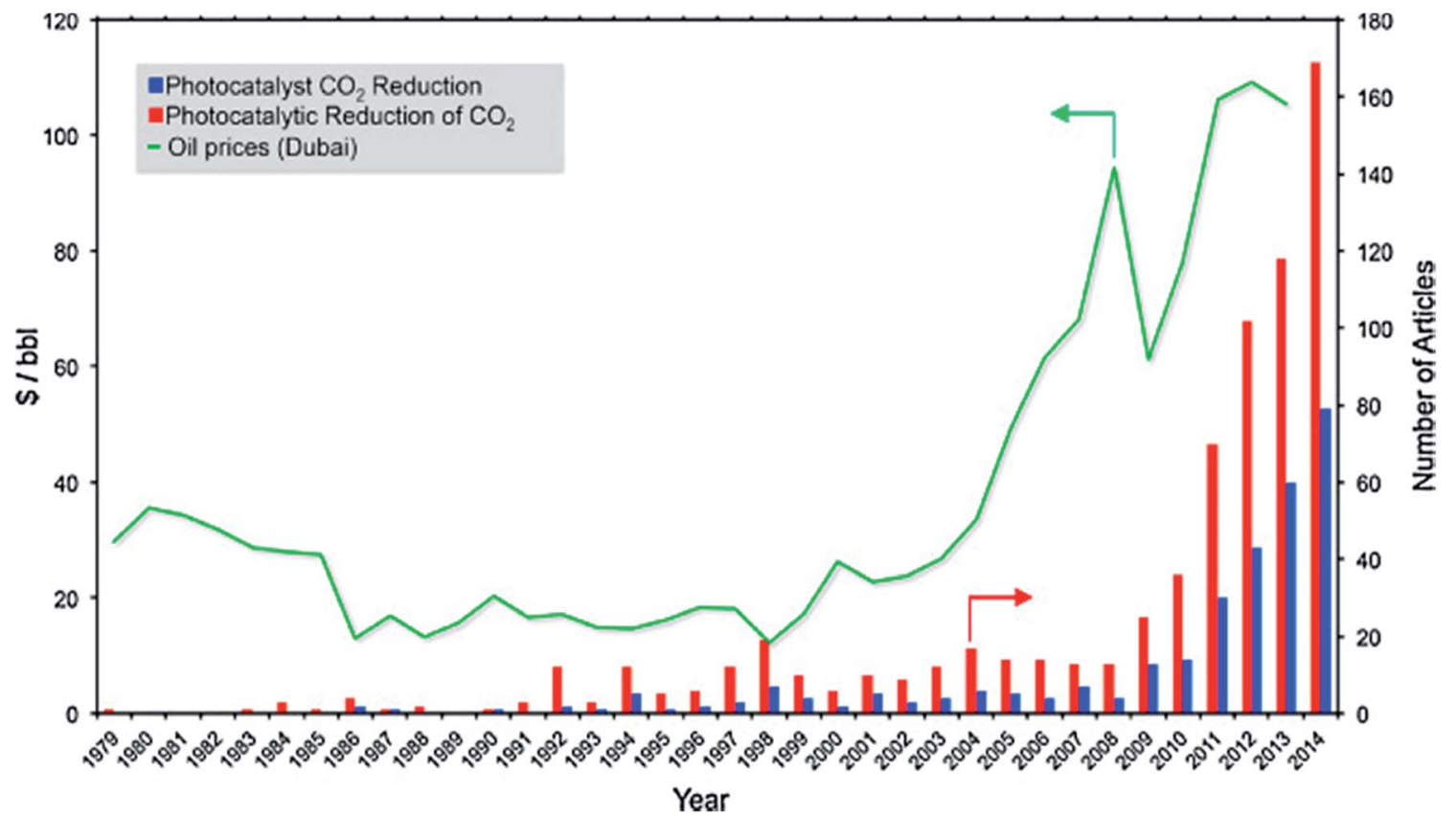

Fig. 1 Timeline for the number of articles published on $\mathrm{CO}_{2}$ photoreduction vs. the price of oil. Reproduced from ref. 11 with permission.

used for solar-driven reactions. They possess relatively high stability, are low cost and absorb light consisting of photons with energy equal to or greater than their bandgap. ${ }^{40}$ This very diverse group of materials includes both narrow and wide bandgap semiconductors; yet many of them offer a more favourable bandgap than $\mathrm{TiO}_{2}$. Moreover, many recent $\mathrm{CO}_{2} \mathrm{PR}$ developments follow similar trends to those for photocatalytic water splitting, as both processes share similar constraints on energy bands. ${ }^{41-43}$ Specifically, the quest for new semiconductor materials is focused on the following points: ${ }^{27}$

(a) rising the valence band energy to decrease the bandgap,

(b) moving the conduction band to more reductive potentials,

(c) improving the quantum efficiency of exciton formation whilst suppressing charge recombination and

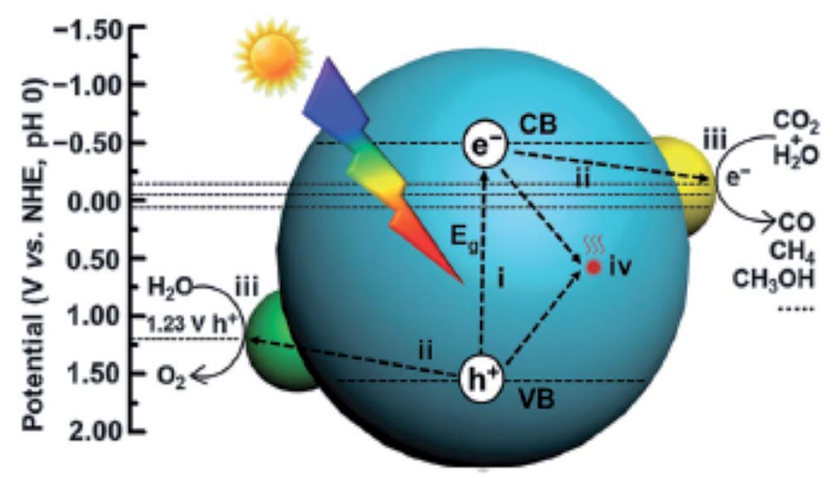

Fig. 2 Schematic illustration of photocatalytic $\mathrm{CO}_{2}$ reduction with $\mathrm{H}_{2} \mathrm{O}$ over a heterogeneous photocatalyst. The dotted lines indicate the thermodynamic potentials for water oxidation and $\mathrm{CO}_{2}$ reduction into $\mathrm{CO}, \mathrm{CH}_{3} \mathrm{OH}$ and $\mathrm{CH}_{4}$. Reproduced from ref. 26 with permission. (d) using novel nanoscale morphologies to provide a large surface area with multiple photocatalytically active sites.

To achieve the quest mentioned above, different methods have been proposed previously and are reviewed in the following sections.

\section{Non- $\mathrm{TiO}_{2}$ materials for $\mathrm{CO}_{2}$ photoreduction reactions}

Although the position of conduction and valence bands is important for photocatalytic properties, the morphology of materials plays a critical role. Furthermore, manipulating the microstructure has also shown to alter the bandgap energy, ${ }^{44}$ suppress the charge recombination, ${ }^{45}$ enhance the diffusion of electrons towards the surface of photocatalysts, ${ }^{46}$ induce quantum confinement effects $^{47}$ and provide more photocatalytic active sites, thereby enhancing the photocatalytic performance. In this section, nanostructured non- $\mathrm{TiO}_{2}$ semiconducting materials for $\mathrm{CO}_{2} \mathrm{PR}$ published in the last two decades are reviewed, including metal sulphides, oxides, oxynitrides and nitrides.

\subsection{Sulphides}

Sulphide semiconductors received a lot of attention for $\mathrm{CO}_{2} \mathrm{PR}$. This was because their valence band, made of $3 p$ orbitals of the sulphur atoms, is located higher than those of their oxide analogues, resulting in the conduction band being more reductive. ${ }^{42}$ Many sulphides have a narrow bandgap (e.g., $\mathrm{PbS}$ and $\mathrm{Bi}_{2} \mathrm{~S}_{3}$ ), with the absorption onset in the visible and infrared regions. Amongst sulphide semiconductors, ZnS and CdS were the most studied sulphides for $\mathrm{CO}_{2} \mathrm{PR}$. $\mathrm{ZnS}$ is a wide bandgap semiconductor ( $E_{\mathrm{g}}=3.66 \mathrm{eV}$ in the bulk); however, it possesses 
a strong reducing power of the conduction band $\left(E_{\mathrm{CB}}=-1.85 \mathrm{~V}\right.$ vs. the NHE at $\mathrm{pH} 7)^{48}$

Zinc-based materials. The surface area of the photocatalyst is one of the key factors that can significantly affect the efficiency of the photocatalytic process. Koči et al. proposed the immobilization of ZnS on montmorillonite, a representative natural clay mineral, which possesses a high surface area and layered structure, to optimise the efficiency of the $\mathrm{CO}_{2} \mathrm{PR}$ (Table 1 entry 1). ${ }^{49}$ The study demonstrated that the amount of ZnS loaded affected the degree of agglomeration that consequently influenced the electronic configuration as well as the efficiency of the $\mathrm{ZnS} /$ montmorillonite nanocomposite in the $\mathrm{CO}_{2} \mathrm{PR}$ under UV irradiation $(254 \mathrm{~nm})$. A similar approach was demonstrated by Petra et al., in which ZnS was loaded onto large-surface-area $\mathrm{SiO}_{2}\left(340 \mathrm{~m}^{2} \mathrm{~g}^{-1}\right)$ to reduce $\mathrm{CO}_{2}$ to formate using 2,5-dihydrofuran as the reducing agent..$^{50}$ The study revealed that the loading amount of $\mathrm{ZnS}$ significantly affected the yield and the optimal loading was $13 \%$ of $\mathrm{ZnS}$ into $\mathrm{SiO}_{2}$, resulting in $7 \mathrm{mmol}$ $\mathrm{g}^{-1} \mathrm{~h}^{-1}$ of $\mathrm{HCOOH}$. Nonetheless, the fabricated samples with coverages above $7 \%$ of $\mathrm{ZnS}$ on the $\mathrm{SiO}_{2}$ matrix could suppress the photo-corrosion of $\mathrm{ZnS}$ to $\mathrm{Zn}(0)$, which is the major disadvantage of sulphides in an aqueous dispersion because the oxidation of lattice $\mathrm{S}^{2-}$ ions leads to elemental sulphur and eventually to sulphate. ${ }^{51}$

Meng et al. proposed the co-doping of $\mathrm{Cd}$ and $\mathrm{Cu}$ into $\mathrm{ZnS}$ as one of the most active and optimised design routes for metal sulphide photocatalysts so far. ${ }^{52}$ It was found that the doping of $\mathrm{Cu}$ could promote the formation of $\mathrm{S}$ vacancies and narrow the bandgap energy of $\mathrm{ZnS}$, whereas surface modification of $\mathrm{Cu}-$ doped $\mathrm{ZnS}$ with $\mathrm{Cd}^{2+}$ enhanced the product selectivity towards $\mathrm{HCOOH}(99 \%)$ under solar light irradiation. Recently, solid solutions of $\mathrm{ZnLn}_{2} \mathrm{~S}_{4}$ with a flower-like microstructure decorated with a cubic $\mathrm{CeO}_{2}$ co-catalyst have been shown to exhibit enhanced $\mathrm{CH}_{3} \mathrm{OH}$ production $\left(0.542 \mu \mathrm{mol} \mathrm{g}_{\text {catalyst }}{ }^{-1} \mathrm{~h}^{-1}\right)$ when compared to pristine $\mathrm{CeO}_{2}$ and $\mathrm{ZnLn}_{2} \mathrm{~S}_{4}(0.139$ and $0.073 \mu \mathrm{mol}$ $\mathrm{g}_{\text {catalyst }}{ }^{-1} \mathrm{~h}^{-1}$, respectively) under visible light irradiation $(\lambda \geq$ $420 \mathrm{~nm}) .^{53}$

Cadmium-based materials. CdS $(2.4 \mathrm{eV}$ and the absorption onset at $520 \mathrm{~nm}$ ) is a narrow bandgap metal sulphide photocatalyst. Hence, CdS suffers from rapid recombination of photogenerated electron-hole pairs. In order to enhance the separation of photogenerated electron-hole pairs, surfacephase junctions deduced by the same semiconductors were proposed. Chai et al. fabricated a mixed-phase CdS that is composed of wurtzite and zinc-blende crystalline phases recently (Table 1 entry 2). ${ }^{54}$ The fabricated sample exhibited a long photogenerated electron lifetime and efficient charge transfer. The maximum $\mathrm{CO}$ and $\mathrm{CH}_{4}$ evolution rate was 1.61 and $0.31 \mu \mathrm{mol} \mathrm{h}^{-1} \mathrm{~g}^{-1}$, respectively, and these production rates were maintained even after $100 \mathrm{~h}$.

The conduction band of CdS is less reductive $\left(E_{\mathrm{CB}}=-0.9 \mathrm{~V}\right.$ at $\mathrm{pH} 7$ vs. NHE) than that of $\mathrm{ZnS}$. Therefore, CdS is always decorated with noble metals, such as Ag. For instance, Zhu et al. proposed that the loaded $\mathrm{Ag}$ could act as an electron trap as well as an active site for $\mathrm{CO}_{2} \mathrm{PR}$ on CdS..$^{55}$ The photoproduction of $\mathrm{CO}$ was improved by three times when compared with that obtained with bare CdS. Alternatively, CdS can be supported with other wide bandgap semiconductors to enhance its reducing power for $\mathrm{CO}_{2} \mathrm{PR}$. Kisch et al. found that the coupling of CdS with $\mathrm{ZnS}$ strongly enhanced the $\mathrm{CO}_{2} \mathrm{PR}$ activity when compared to $\mathrm{SiO}_{2}{ }^{-}$ supported CdS or ZnS samples because CdS and ZnS can absorb light at $\leq 530 \mathrm{~nm}$ and $\leq 330 \mathrm{~nm}$, respectively. ${ }^{56}$ The study reported that $5 \mathrm{wt} \% \mathrm{CdS}$ loaded onto $\mathrm{ZnS}$ induced a 40 -fold and 16-fold enhancement in the production of $\mathrm{HCOOH}(\sim 80 \mathrm{mM}, \lambda$ $\geq 320 \mathrm{~nm}, 3 \mathrm{~h}$ ) when compared to unmodified CdS and $\mathrm{ZnS}$, respectively. This strong enhancement was attributed to the electronic semiconductor-support interaction effect that improved the charge separation efficiency of the coupled semiconductor system. A similar observation was also reported by Kočí et al. recently, in which core-shell CdS/ZnS nanoparticles deposited on montmorillonite prepared by a one-pot synthesis exhibited enhanced $\mathrm{CO}_{2} \mathrm{PR}$ activity in water under UV irradiation $(\lambda=365 \mathrm{~nm}) .{ }^{57}$ The increase in the yield was due to the enhanced charge separation of CdS cores by ZnS shells, the increase of surface area and the inhibition of CdS photocorrosion. $\mathrm{CO}_{2} \mathrm{PR}$ performed with $\mathrm{CdS}$ coupled with $\mathrm{Bi}_{2} \mathrm{~S}_{3}$, having smaller bandgap energy than CdS, was also reported. ${ }^{59}$ The $\mathrm{Bi}_{2} \mathrm{~S}_{3} / \mathrm{CdS}$ nanocomposite fabricated with $15 \mathrm{wt} \% \mathrm{Bi}_{2} \mathrm{~S}_{3}$ exhibited the highest methanol production from $\mathrm{CO}_{2}$ (6.13 mmol g ${ }^{-1} \mathrm{~h}^{-1}$, Table 1 entry 3), which was at least $50 \%$ higher than those obtained with bare $\mathrm{Bi}_{2} \mathrm{~S}_{3}\left(3.14 \mathrm{mmol} \mathrm{g}^{-1} \mathrm{~h}^{-1}\right)$ and CdS (2.01 $\left.\mathrm{mmol} \mathrm{g}^{-1} \mathrm{~h}^{-1}\right)$, under visible light irradiation. The enhanced photocatalytic activity suggested that the establishment of a heterojunction between $\mathrm{CdS}$ and $\mathrm{Bi}_{2} \mathrm{~S}_{3}$ could improve charge separation and subsequently prolong the lifetime of photogenerated electron-hole pairs. Moreover, the surface area of the $\mathrm{Bi}_{2} \mathrm{~S}_{3} / \mathrm{CdS}$ nanocomposite, which was 24-27 $\mathrm{m}^{2} \mathrm{~g}^{-1}$, was slightly higher than those of the bare CdS and $\mathrm{Bi}_{2} \mathrm{~S}_{3}$ (12 and $21 \mathrm{~m}^{2} \mathrm{~g}^{-1}$, respectively). Hence, the synergetic effect of surface area and the heterojunction established between these two semiconductors had significantly improved the overall performance in $\mathrm{CO}_{2} \mathrm{PR}$. Increasing the specific surface area does not only provide more active sites for the photocatalytic reaction, but also affects the optical properties of the material. For instance, Jin et al. recently proposed that by increasing the length-to-width ratio of $\mathrm{Bi}_{2} \mathrm{~S}_{3}$ nanoribbons, which increased the bandgap energy of $\mathrm{Bi}_{2} \mathrm{~S}_{3}$ from 1.22 to $1.38 \mathrm{eV}$, the $\mathrm{CH}_{3} \mathrm{OH}$ yield obtained was increased from 25.94 to $32.02 \mu \mathrm{mol} \mathrm{g}$ catalyst $^{-1} \mathrm{~h}^{-1}$ under visible light irradiation $(\lambda \geq 420 \mathrm{~nm}){ }^{61}$ However, the coupling of $\mathrm{Bi}_{2} \mathrm{~S}_{3}$ nanoribbons with CdS was not demonstrated. Hence, it will be interesting to see the performance of $\mathrm{Bi}_{2} \mathrm{~S}_{3}$ nanoribbons/ $\mathrm{CdS}$ nanocomposites in the $\mathrm{CO}_{2} \mathrm{PR}$.

The coupling of CdS with other metal oxides, such as $\mathrm{WO}_{3}$, has been demonstrated recently. For instance, Jin et al. proposed the coupling of $\mathrm{WO}_{3}$ hollow spheres with CdS to form a hierarchical $Z$-scheme to increase the $\mathrm{CO}_{2} \mathrm{PR}$ efficiency. ${ }^{62}$ The coupling of $\mathrm{WO}_{3}-\mathrm{CdS}$ had greatly enhanced the photoconversion of $\mathrm{CO}_{2}$ to $\mathrm{CH}_{4}$ to $\sim 1.0 \mu \mathrm{mol} \mathrm{g} \mathrm{g}_{\text {catalyst }}{ }^{-1} \mathrm{~h}^{-1}$ under visible irradiation $(\lambda \geq 420 \mathrm{~nm})$, whereas pristine $\mathrm{WO}_{3}$ and $\mathrm{CdS}$ only produced trace amounts of $\mathrm{CH}_{4}$.

Recently, the synthesis of $\mathrm{Zn}_{x} \mathrm{Cd}_{1-x} \mathrm{~S}$ solid solutions has attracted extensive attention due to their versatility in tuning the band structures. ${ }^{63-65}$ Moreover, the introduction of $\mathrm{Zn}$ can 
Table 1 Photocatalytic $\mathrm{CO}_{2}$ reduction yields obtained with various photocatalysts

Product(s) of $\mathrm{CO}_{2}$ photoreduction

No. Photocatalyst $\quad\left(\mu \mathrm{mol} \mathrm{g}_{\text {catalyst }}^{-1} \mathrm{~h}^{-1}\right)$

Light source

Ref.

Sulphides

1. ZnS/montmorillonite nanocomposite

$\mathrm{CH}_{4} 1.17$

CO 0.125

2. CdS wurtzite/zinc-blende nanohybrid

3. $\mathrm{Bi}_{2} \mathrm{~S}_{3} / \mathrm{CdS}$

CdS wurtzite/zinc-blende nanohybrid

4. $\quad \mathrm{Zn}_{x} \mathrm{Cd}_{1-x} \mathrm{~S}$ solid solution and tetra(4-carboxyphenyl)porphyrin iron(III) chloride

5. $\quad \mathrm{Cu}_{2} \mathrm{~S} / \mathrm{CuS}$

6. $\mathrm{RuO}_{2}$-modified $\mathrm{Cu}_{x} \mathrm{Ag}_{y} \mathrm{In}_{z} \mathrm{Zn}_{k} \mathrm{~S}_{m}$ solid solutions

\section{Oxides}

$7 . \quad \mathrm{ZnO}$

8. $\quad \mathrm{NiO}$

9. Fluffy mesoporous $\mathrm{ZnO}$

10. N-doped ZnO

11. ZnO plates

12. Ultralong and ultrathin single crystal $\mathrm{Zn}_{2} \mathrm{GeO}_{4}$ nanoribbons

13. $\mathrm{Zn}_{2} \mathrm{GeO}_{4}$ nanorods

14. $\mathrm{RuO}_{2}$ and Pt co-loaded

$\mathrm{Zn}_{1.7} \mathrm{GeN}_{1.8} \mathrm{O}$ nano-sheaves

15. $\mathrm{ZnGa}_{2} \mathrm{O}$ nanosheet-scaffolded microspheres

16. $\mathrm{Zn}_{2} \mathrm{SnO}_{4}$ hexagonal nanoplates

17. Ce-doped $\mathrm{ZnFe}_{2} \mathrm{O}_{4}$

18. Quasi-cubic $\mathrm{WO}_{3}$

19. Ultrathin single crystal $\mathrm{WO}_{3}$

20. Ultrathin $\mathrm{W}_{18} \mathrm{O}_{49}$

21. $\mathrm{Bi}_{2} \mathrm{WO}_{6}$ nanosheets with

well-defined $\{001\}$ facets

$\mathrm{BiWO}_{6}$

$\mathrm{NaNbO}_{3}$ nanowires

$\mathrm{KNb}_{3} \mathrm{O}_{8}$ nanobelts

$\mathrm{HNb}_{3} \mathrm{O}_{8}$ nanobelts

$\mathrm{SrNb}_{2} \mathrm{O}_{6}$ nanorods

$3 \% \mathrm{NiO}_{x}-\mathrm{Ta}_{2} \mathrm{O}_{5}-1 \%$ immobilised

on reduced graphene

28. Core-shell Ni/NiO-loaded N-InTaO

29. $\mathrm{LaTa}_{7} \mathrm{O}_{19}$

30. $\quad \mathrm{CaTa}_{4} \mathrm{O}_{11}$

31. $1.0 \mathrm{wt} \%$ Ag-modified Ba-doped $\mathrm{NaTaO}_{3}$

32. $\mathrm{K}_{2} \mathrm{YTa}_{5} \mathrm{O}_{15}$

33. $\mathrm{Ag}$-modified $\mathrm{Ga}_{2} \mathrm{O}_{3}$

34. Lamellar $\mathrm{BiVO}_{4}$

35. $\mathrm{CuGa}_{1-x} \mathrm{Fe}_{x} \mathrm{O}$

36. CoAl-layered double hydroxides

\section{Oxynitrides}

37. Porous TaON

38. $\mathrm{ZnAl}_{2} \mathrm{O}_{4}$-modified $\mathrm{ZnGa}_{2} \mathrm{ON}$

Nitrides

39. GaN

40. $\mathrm{Rh} / \mathrm{Cr}_{2} \mathrm{O}_{3}$-decorated $\mathrm{GaN}$ nanowires

CO 1.61

$\mathrm{CH}_{4} 0.31$

CO 1.61

$\mathrm{CH}_{4} 0.31$

$\mathrm{CH}_{3} \mathrm{OH} 6.13 \mathrm{mmol} \mathrm{g}_{\text {catalyst }}{ }^{-1} \mathrm{~h}^{-1}$

CO $1.28 \mu \mathrm{mol}$

$\mathrm{CH}_{4} 46.21 \pm 6.50 \mu \mathrm{mol} \mathrm{m}{ }^{-2} \mathrm{~h}^{-1}$

$\mathrm{CH}_{3} \mathrm{OH} 118.5$

\section{$\mathrm{CH}_{3} \mathrm{OH} 325$ \\ $\mathrm{CH}_{3} \mathrm{OH} 388$ \\ CO 0.73 \\ CO 0.04 \\ CO $763.5 \mathrm{ppm} \mathrm{g}_{\text {catalyst }}{ }^{-1} \mathrm{~h}^{-1}$ \\ $\mathrm{CH}_{4}$ 205.2 $\mathrm{ppm} \mathrm{g}_{\text {catalyst }}{ }^{-1} \mathrm{~h}^{-1}$}

$\mathrm{CH}_{4} 25$

CO $179 \mathrm{ppm} \mathrm{g}_{\text {catalyst }}{ }^{-1} \mathrm{~h}^{-1}$

$\mathrm{CH}_{4} 35 \mathrm{ppm} \mathrm{g}_{\text {catalyst }}{ }^{-1} \mathrm{~h}^{-1}$

$\sim 55$

69

47

$\mathrm{CO} \sim 20$

$\sim 0.34$

$\sim 1.1$

$\mathrm{CH}_{4} 2200$

1.1

$\mathrm{CH}_{3} \mathrm{OH} 32.6$

$\mathrm{CH}_{4} 653 \mathrm{ppm} \mathrm{g}_{\text {catalyst }}{ }^{-1} \mathrm{~h}^{-1}$

CO 3.58

CO 1.71

CO 51.2

$\mathrm{CH}_{3} \mathrm{OH} 197.92$

$\mathrm{CH}_{3} \mathrm{OH} 160$

CO 50

$\mathrm{CO} 70$

$\mathrm{CO} \sim 50$

CO 91.9

CO 10.5

$\mathrm{CH}_{3} \mathrm{OH} 5.52$

$\mathrm{CO} \sim 9.2$

$\mathrm{CH}_{4} 4.2$

$\mathrm{CH}_{3} \mathrm{CHO} 0.52$

$\mathrm{C}_{2} \mathrm{H}_{5} \mathrm{OH} 2.03$

$\mathrm{CH}_{4} 9.2$
UV $8 \mathrm{~W} \mathrm{Hg} \operatorname{lamp}(\lambda=254 \mathrm{~nm})$

49

$300 \mathrm{~W}$ Xe lamp $(\lambda \geq 420 \mathrm{~nm})$

$500 \mathrm{~W}$ Xe lamp $(\lambda \geq 320 \mathrm{~nm})$

$300 \mathrm{~W}$ Xe lamp $(\lambda \geq 420 \mathrm{~nm})$

$300 \mathrm{~W}$ Xe lamp $(420 \mathrm{~nm}<\lambda<780 \mathrm{~nm}$

A.M 1.5 simulated sunlight

$1000 \mathrm{~W}$ Xe lamp $(\lambda>400 \mathrm{~nm})$

60

69

$355 \mathrm{~nm}$ laser beam

74

$8 \mathrm{~W}$ fluorescent tube $\left(7 \mathrm{~mW} \mathrm{~cm}^{-2}\right)$

75

$300 \mathrm{~W}$ Xe arc lamp

76

$300 \mathrm{~W}$ Xe arc lamp

77

$300 \mathrm{~W}$ Xe arc lamp

78

$300 \mathrm{~W}$ Xe arc lamp $(\lambda>420 \mathrm{~nm})$

79

$300 \mathrm{~W}$ Xe arc lamp with an IR cut filter $300 \mathrm{~W}$ Xe arc lamp

Visible light

$300 \mathrm{~W}$ Xe lamp

$300 \mathrm{~W}$ Xe arc lamp

Full-arc Xe lamp

$300 \mathrm{~W}$ Xe arc lamp

$300 \mathrm{~W}$ Xe lamp $(\lambda>420 \mathrm{~nm})$

$300 \mathrm{~W}$ Xe lamp

$350 \mathrm{~W}$ Xe lamp

$400 \mathrm{~W} \mathrm{Hg} \mathrm{lamp}$

$400 \mathrm{~W}$ metal halide lamp

Xe lamp $(100 \mathrm{~mW}, 390 \leq \lambda \leq 770$

$400 \mathrm{~W}$ Hg lamp

$400 \mathrm{~W}$ Hg lamp

$4000 \mathrm{~W}$ Hg lamp

UV light

$300 \mathrm{~W}$ Xe lamp (full spectrum)

$300 \mathrm{~W}$ Xe arc lamp

$500 \mathrm{~W}$ Xe lamp

$300 \mathrm{~W}$ Xe lamp

100

$300 \mathrm{~W}$ Xe lamp $(\lambda \geq 420 \mathrm{~nm})$

101 
manipulate the structure of the surface atoms in CdS, which influences the adsorption or desorption of the reactants, intermediates and products in photocatalytic reactions. ${ }^{58}$ In a very recent study, $\mathrm{Li}$ et al. integrated the well-defined floccule-like $\mathrm{Zn}_{x} \mathrm{Cd}_{1-x} \mathrm{~S}$ solid solution (Fig. 3) with tetra(4carboxyphenyl)porphyrin iron(III) chloride for $\mathrm{CO}_{2}$ photoreduction under visible light irradiation. ${ }^{58}$ The optimised photocatalyst, which was synthesized with $\mathrm{Zn}\left(\mathrm{NO}_{3}\right)_{2} \cdot 6 \mathrm{H}_{2} \mathrm{O}$ and $\mathrm{Cd}\left(\mathrm{NO}_{3}\right)_{2} \cdot 4 \mathrm{H}_{2} \mathrm{O}$ at $0.25: 0.75$ (ZCS-1, Fig. 3), produced 1.28 $\mu \mathrm{mol}$ of CO with a selectivity of $93 \%$ after $4 \mathrm{~h}$. However, pristine $\mathrm{CdS}$ and other synthesized $\mathrm{Zn}_{x} \mathrm{Cd}_{1-x} \mathrm{~S}$ solid solutions produced less than $0.4 \mu \mathrm{mol}$ of $\mathrm{CO}$ under visible light irradiation. The superior performance of ZCS-1 was attributed to the presence of sulphur vacancies that trapped photogenerated electrons, provided $\mathrm{CO}_{2}$ adsorption sites and facilitated the interaction between the $\mathrm{Zn}_{x} \mathrm{Cd}_{1-x} \mathrm{~S}$ solid solution and tetra(4carboxyphenyl)porphyrin iron(III) chloride, resulting in efficient interfacial electron transfer for the subsequent photocatalytic reduction reaction.

Copper-based materials. $\mathrm{Cu}_{2-x} \mathrm{~S}$, which have been shown to exhibit localised surface resonance in the near infrared region, and $\mathrm{CuS}$, which has a direct bandgap of $2.0 \mathrm{eV}$, are nearly ideal for optimal sunlight absorption. ${ }^{\mathbf{6 , 6 7}}$ By carefully controlling the anodization voltage and temperature during the electrochemical anodization of copper foil and copper-coated Kapton substrates, in sodium sulphide electrolyte, copper sulphides with a nanowall nanostructure were obtained (Fig. 4). ${ }^{60}$ The sample anodized with $1.5 \mathrm{~V}$ at $5{ }^{\circ} \mathrm{C}$ exhibited the highest methane formation in the $\mathrm{CO}_{2} \mathrm{PR}$ (Table 1 entry 5) under the irradiation of simulated sunlight. At low voltage and temperature, sulphur diffusion was low, leading to a lower concentration of excess sulphur in the sample that yielded $\mathrm{Cu}_{2} \mathrm{~S}$. As a result, less bulk $\mathrm{Cu}$ vacancy defects were formed within the sample. $\mathrm{Cu}_{2} \mathrm{~S}$ exhibited higher charge mobility than the CuS nanostructured array, which was obtained at high temperature and high voltage.

To engineer the bandgap energy of the photocatalyst that matches the solar spectrum, a solid solution with large and small bandgap semiconductors was proposed. For instance, Arai et al. used the Cu-based sulphide complex $\mathrm{Cu}_{2} \mathrm{ZnSnS}_{4}$ with a direct bandgap of $1.5 \mathrm{eV}$ and a large optical absorption coefficient and obtained a high selectivity of the photoelectrochemical $\mathrm{CO}_{2}$ reduction reaction $(>80 \%) .{ }^{68}$ The $\mathrm{Cu}$-based sulphide complex reported by Liu et al. showcased that the $\mathrm{Cu}$ based sulphide complex was able to reduce $\mathrm{CO}_{2}$ under visible light irradiation in the presence of a $\mathrm{Ru}$ co-catalyst. ${ }^{69}$ The $\mathrm{Ru}-$ $\mathrm{Cu}_{x} \mathrm{Ag}_{y} \mathrm{In}_{z} \mathrm{Zn}_{k} \mathrm{~S}_{m}$ solid solutions induced the formation of methanol in $\mathrm{CO}_{2} \mathrm{PR}$ under visible light irradiation (Table 1 entry 6). Although the study reported that the optimal performance could be obtained through the elemental composition manipulation, the nanostructures of the sulphide complex were not revealed. It is therefore questionable whether the efficiency of these photocatalysts could be further enhanced through the manipulation of their microstructures. Moreover, the stability of metal sulphates in most of the studies has not been demonstrated, and this should be emphasized more in future work.
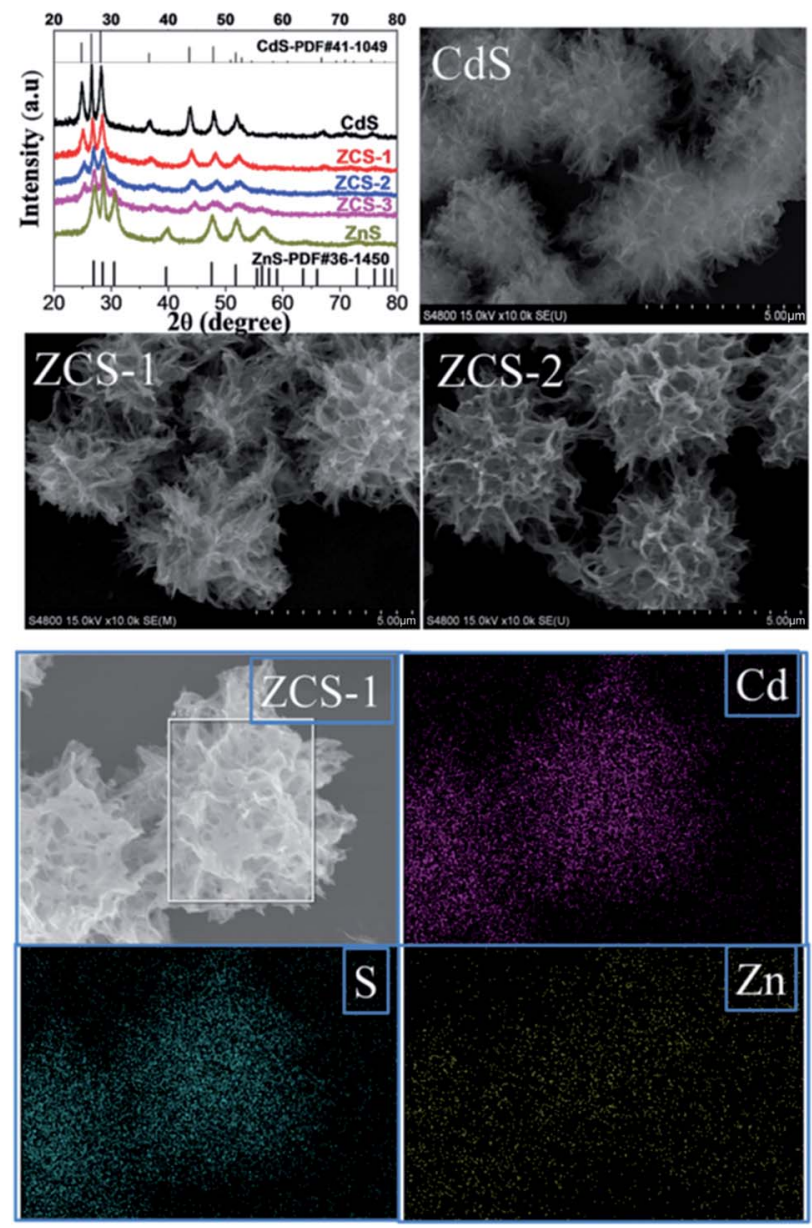

Fig. 3 XRD patterns, SEM images and EDX mapping of the synthesized $\mathrm{CdS}$ and $\mathrm{Zn}_{x} \mathrm{Cd}_{1-x} \mathrm{~S}$ solid solutions. Reproduced from ref. 58 with permission.

\subsection{Oxides}

Semiconducting oxides have been widely used as photocatalysts because of their stability and resistance to photocorrosion under irradiation. Hence, oxides have been used for photooxidation and photoreduction reactions. The intrinsic properties of metal oxides play a critical role in determining their feasibility for $\mathrm{CO}_{2} \mathrm{PR}$. For example, $\mathrm{CO}_{2} \mathrm{PR}$ was observed for $\mathrm{p}$-type $\mathrm{NiO}$ covalently linked with a $\mathrm{Zn}$ porphyrin light-harvesting sensitizer and rhenium bipyridine system, whereas the CO oxidation reaction was observed when a similar system was coupled with n-type NiO. ${ }^{70}$ There are two main groups of metal oxides with a closed-shell electronic configuration that have been at the centre of interest for a $\mathrm{CO}_{2} \mathrm{PR}$ system. The first group includes octahedrally coordinated $\mathrm{d}^{0}$ transition metal ions $\left(\mathrm{Ti}^{4+}\right.$, $\mathrm{Zr}^{4+}, \mathrm{Nb}^{5+}, \mathrm{Ta}^{5+}, \mathrm{V}^{5+}$, and $\left.\mathrm{W}^{6+}\right)$. Apart from $\mathrm{TiO}_{2}$, which is the most prominent member of this group, other binary oxides (e.g., $\mathrm{ZrO}_{2}, \mathrm{Nb}_{2} \mathrm{O}_{5}$, and $\mathrm{Ta}_{2} \mathrm{O}_{5}$ ) have been used in $\mathrm{CO}_{2} \mathrm{PR}$. A number of more complex oxides referred to as titanates, niobates, tantalates, etc. ${ }^{71,72}$ are often found in a perovskite composite, $\mathrm{AMO}_{3}$ ( $\mathrm{A}=$ electropositive cation and $\mathrm{M}=$ transition metal; e.g., $\mathrm{SrTiO}_{3}$ and $\mathrm{NaNbO}_{3}$ ), or in perovskite-related structures. Since 


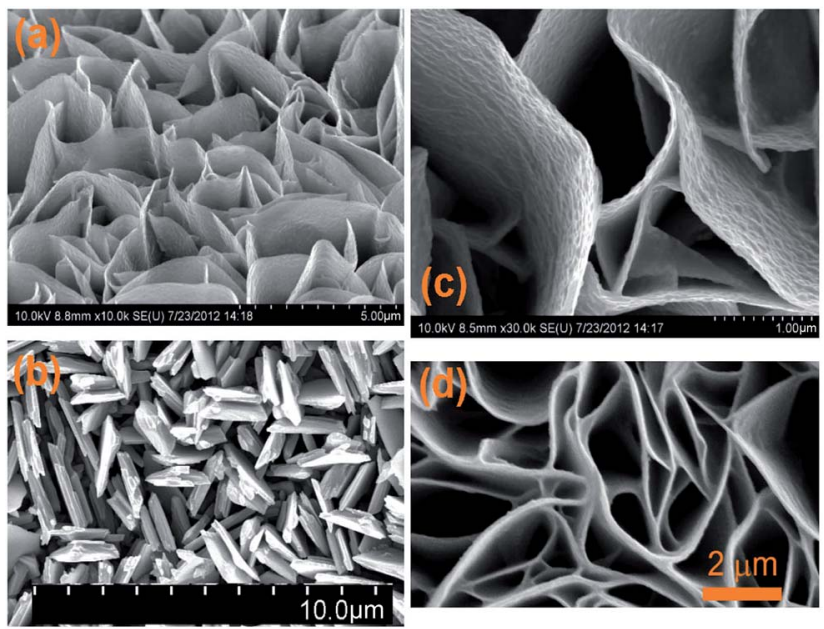

Fig. 4 SEM images of the copper sulphide nanowalls oriented vertically to the copper foil anodized at $1.5 \mathrm{~V}$ at room temperature (a and $\mathrm{c}$ ), and $3.0 \mathrm{~V}(\mathrm{~b})$ and $1.5 \mathrm{~V}$ (d) at $5{ }^{\circ} \mathrm{C}$. Reproduced from ref. 60 with permission.

a recent published review has covered the use of perovskite oxide nanomaterials for $\mathrm{CO}_{2}$ photoreduction, ${ }^{73}$ this area will not be further discussed here. The second group includes main group metal oxides in a $\mathrm{d}^{10}$ configuration with a general formula of $\mathrm{M}_{y} \mathrm{O}_{z}$ or $\mathrm{A}_{x} \mathrm{M}_{y} \mathrm{O}$, where $\mathrm{M}$ represents $\mathrm{Ga}$, Ge, In, Sn, or $\mathrm{Sb}$. Many of these photocatalytically active binary and ternary oxides initially found application in photocatalytic water splitting, but they have very recently started to be utilised for $\mathrm{CO}_{2}$ PR. $^{73}$

Zinc-based materials. ZnO has been widely used in the photodegradation of organic dyes and chemicals due to its direct and wide bandgap (3.37 eV). ${ }^{\mathbf{1 0 3}}$ Additionally, the bandgap and photocatalytic mechanism of $\mathrm{ZnO}$ are similar to those of $\mathrm{TiO}_{2}$, and thus, $\mathrm{ZnO}$ was also used for $\mathrm{CO}_{2} \mathrm{PR}$. To compare the $\mathrm{CO}_{2}$ photoreduction efficiency of $\mathrm{ZnO}$ with that of other commonly used wide bandgap semiconductors, Yahaya et al. employed commercially available $\mathrm{TiO}_{2}, \mathrm{ZnO}$ and $\mathrm{NiO}$ as photocatalysts for $\mathrm{CO}_{2}$ photoreduction under $355 \mathrm{~nm}$ UV laser irradiation. ${ }^{74}$ Among the samples, $\mathrm{ZnO}$ and $\mathrm{NiO}$ produced high yields of methanol (325 and $388 \mu \mathrm{mol} \mathrm{g}{ }^{-1} \mathrm{~h}^{-1}$ over $1.5 \mathrm{~h}$, respectively, Table 1, entries 7 and 8); whereas $\mathrm{TiO}_{2}$ had the lowest production yield. In order to enhance the light absorption of commercial $\mathrm{ZnO}$ in the $\mathrm{UV}$-vis region, $\mathrm{ZnO}$ was calcined to $350{ }^{\circ} \mathrm{C}$ and the $\mathrm{ZnO}$ obtained was immobilised onto a stainless-steel mesh to reduce the agglomeration of the photocatalyst. ${ }^{104}$ The maximum conversion of $\mathrm{CO}_{2}$ achieved was $11.9 \%$ (i.e., percentage of $\mathrm{CH}_{4}$ produced from $\mathrm{CO}_{2}$ in the presence of a $\mathrm{CH}_{4}$ reductant). A study revealed that the microstructure of $\mathrm{ZnO}$ played a more vital role than doping of $\mathrm{ZnO}$ with nitrogen ( $\mathrm{N}-\mathrm{ZnO})$, even though the latter showed enhanced light absorption from 400 to $650 \mathrm{~nm} .^{75}$ A fluffy mesoporous structured $\mathrm{ZnO}$ with a surface area of $29.7 \mathrm{~m}^{2} \mathrm{~g}^{-1}$ exhibited enhanced CO production $\left(0.73 \mu \mathrm{mol} \mathrm{g}_{\text {catalyst }}{ }^{-1} \mathrm{~h}^{-1}\right.$, Table 1 , entry 9) under UV-vis light irradiation when compared to the $\mathrm{N}$-doped ZnO $\left(1.2 \mathrm{~m}^{2} \mathrm{~g}^{-1}, 0.04 \mu \mathrm{mol} \mathrm{g}_{\text {catalyst }}{ }^{-1} \mathrm{~h}^{-1}\right.$, Table 1, entry 10). A separate publication reported that $\mathrm{ZnO}$ plates with porous rectangular and assembled hexagonal morphologies $\left(15.5 \mathrm{~m}^{2} \mathrm{~g}^{-1}\right.$, which was about 2.6 times that of the commercial $\mathrm{ZnO}$, Fig. 5) could be obtained by using $\mathrm{NH}_{4} \mathrm{Zn}_{3}(\mathrm{OH})_{6} \mathrm{NO}_{3} \cdot{ }^{76}$ The synthesized $\mathrm{ZnO}$ plates exhibited a much higher production of $\mathrm{CO}$ and $\mathrm{CH}_{4}$ (76.35 and $20.52 \mathrm{ppm} \mathrm{h}^{-1}$, respectively) than the pristine hexagonal $\mathrm{ZnO}$ plates (44.68 and $1.57 \mathrm{ppm} \mathrm{h}^{-1}$ of $\mathrm{CO}$ and $\mathrm{CH}_{4}$, respectively).

Doping has been widely used to extend the light absorption of wide bandgap semiconductors to a longer wavelength region by introducing intra-band states above the valence band. However, this approach tends to increase the recombination rate and decrease the charge mobility of the semiconductor, as discussed in Section 1. To avoid these drawbacks, the introduction of foreign cations into the binary semiconductor was considered instead of doping. For example, the ternary $\mathrm{Zn}_{2} \mathrm{GeO}_{4}$ semiconductor was used for $\mathrm{CO}_{2} \mathrm{PR}$ under UV-vis irradiation. By fabricating ultralong and ultrathin single crystal $\mathrm{Zn}_{2} \mathrm{GeO}_{4}$ nanoribbons, the photocatalytic reduction rate of $\mathrm{CO}_{2}$ into $\mathrm{CH}_{4}$ was greatly enhanced to $25.0 \mu \mathrm{mol} \mathrm{g}_{\text {catalyst }}{ }^{-1} \mathrm{~h}^{-1}$ when compared to that of the bulk $\mathrm{Zn}_{2} \mathrm{GeO}_{4}$ (trace amounts, Table 1, entry 12). ${ }^{77}$ The enhanced photocatalytic efficiency was attributed to the superb crystal quality and higher surface area $\left(28.3 \mathrm{~m}^{2} \mathrm{~g}^{-1}\right)$ when compared to the bulk $\mathrm{Zn}_{2} \mathrm{GeO}_{4}\left(0.75 \mathrm{~m}^{2} \mathrm{~g}^{-1}\right)$, resulting in enhanced separation of photogenerated electron-hole pairs and charge mobility. In the following year, the same group proposed the synthesis of the single crystal $\mathrm{Zn}_{2} \mathrm{GeO}_{4}$ at $40{ }^{\circ} \mathrm{C}$ to optimise the surface area. $^{78}$ As a result, the surface area of the synthesized $\mathrm{Zn}_{2} \mathrm{GeO}_{4}$ nanorods was $33.1 \mathrm{~m}^{2} \mathrm{~g}^{-1}$ which yielded 179 and $35 \mathrm{ppm} \mathrm{g} \mathrm{g}_{\text {catalyst }}{ }^{-1} \mathrm{~h}^{-1}$ of $\mathrm{CO}$ and $\mathrm{CH}_{4}$, respectively. Further increasing the temperature to $100{ }^{\circ} \mathrm{C}$, however, decreased the surface area to $14.8 \mathrm{~m}^{2} \mathrm{~g}^{-1}$, yielding only 3.2 and $0.4 \mathrm{ppm} \mathrm{h}^{-1}$ of $\mathrm{CO}$ and $\mathrm{CH}_{4}$, respectively. By reducing the concentration of the Ge-precursor and the solvothermal time employed in the first study in 2010 (refer to ref. 77) by half, a sheaf-like superstructured $\mathrm{Zn}_{2} \mathrm{GeO}_{4}$ was obtained and reported by the same group in 2012 (Fig. 6). ${ }^{79}$ Although the $\mathrm{CO}_{2} \mathrm{PR}$ of the superstructured $\mathrm{Zn}_{2} \mathrm{GeO}_{4}$ was not reported in this study, the optimised $\mathrm{RuO}_{2}$ and Pt co-loaded $\mathrm{Zn}_{1.7} \mathrm{GeN}_{1.8} \mathrm{O}$ nano-sheaves after nitridation $\left(32.33 \mathrm{~m}^{2} \mathrm{~g}^{-1}\right)$ could produce $\mathrm{CH}_{4}$ with an apparent quantum yield of $0.024 \%$ at $450 \mathrm{~nm}$ (Table 1 entry 14).

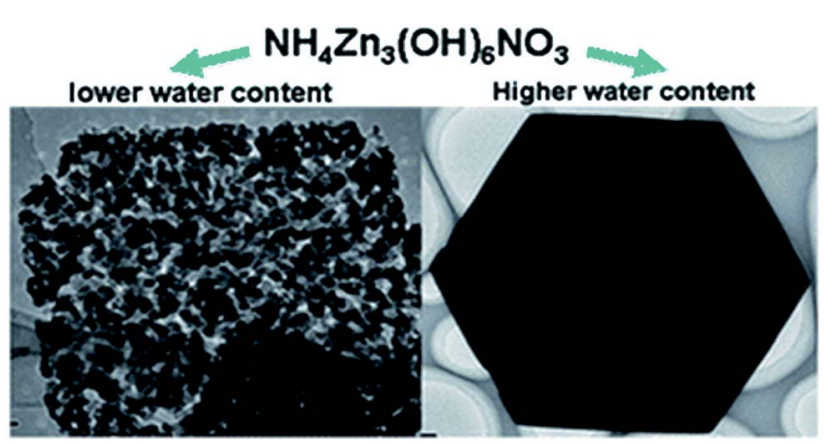

Fig. $5 \mathrm{ZnO}$ synthesized from $\mathrm{NH}_{4} \mathrm{Zn}_{3}(\mathrm{OH})_{6} \mathrm{NO}_{3}$ with $<3 \mathrm{~mL}$ (left) and $>3 \mathrm{~mL}$ (right) of water. Reproduced from ref. 76 with permission. 

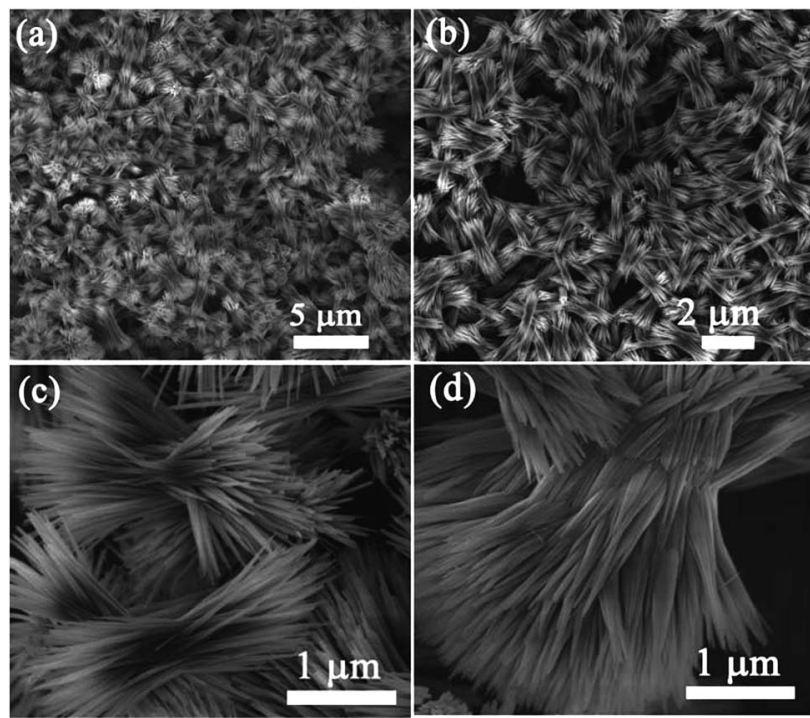

Fig. 6 SEM images of a sheaf-like $\mathrm{Zn}_{2} \mathrm{GeO}_{4}$ superstructure at different magnifications. Reproduced from ref. 79 with permission.

Other nanostructured ternary Zn-based oxides were also proposed by the same group more recently, including $\mathrm{ZnGa}_{2} \mathrm{O}$ nanosheet-scaffolded microspheres ${ }^{80}$ and hexagonal nanoplatetextured $\mathrm{Zn}_{2} \mathrm{SnO}_{4}$ with micro-octahedron architecture for $\mathrm{CO}_{2} \mathrm{PR}$ application. ${ }^{81}$ The unique architecture of the synthesized $\mathrm{ZnGa}_{2} \mathrm{O}$ and $\mathrm{Zn}_{2} \mathrm{SnO}_{4}$ significantly enhanced the separation of photogenerated electron-hole pairs, increased the surface area and extended light absorption. Hence, the methane yield obtained from the $\mathrm{CO}_{2} \mathrm{PR}$ was greatly improved from trace amounts to 69 and $47 \mathrm{ppm} \mathrm{g}_{\text {catalyst }}{ }^{-1} \mathrm{~h}^{-1}$ for the nanostructured $\mathrm{ZnGa}_{2} \mathrm{O}$ and $\mathrm{Zn}_{2} \mathrm{SnO}_{4}$, respectively (Table 1, entries 15 and 16).

To promote co-adsorption of $\mathrm{CO}_{2}$ and $\mathrm{H}_{2} \mathrm{O}$, Guo et al. fabricated $\mathrm{ZnFe}_{2} \mathrm{O}_{4}$ spinels doped with Ce. ${ }^{82}$ By using in situ FTIR, it was found that the $\mathrm{CO}_{2}$ amount adsorbed on the surface of Ce-doped $\mathrm{ZnFe}_{2} \mathrm{O}_{4}$ was much higher than that on pristine $\mathrm{ZnFe}_{2} \mathrm{O}_{4}$. This phenomenon was attributed to the increase of basicity due to the presence of alkaline $\mathrm{CeO}_{2}$ and electron density on the surface of the Ce-doped $\mathrm{ZnFe}_{2} \mathrm{O}_{4}$, thereby increasing the number of adsorption bonds between the $\mathrm{CO}_{2}$ molecules and the surface of the photocatalyst, and activating the $\mathrm{O}=\mathrm{C}$ bond (Fig. 7). The formation of active $\mathrm{b}-\mathrm{CO}_{3}{ }^{2-}$ and $\mathrm{b}$ $\mathrm{HCO}_{3}{ }^{-}$species, which could be readily translated to highly valuable products in the $\mathrm{CO}_{2}$ photoreduction, was detected. Recently, Xiao et al. discovered that ultrafine $\mathrm{ZnFe}_{2} \mathrm{O}_{4}$ nanoparticles with a high specific surface area $\left(112.9 \mathrm{~m}^{2} \mathrm{~g}^{-1}\right)$ could promote the selectivity of the photoproduction of $\mathrm{CH}_{3} \mathrm{CHO}$ over $\mathrm{CH}_{3} \mathrm{CH}_{2} \mathrm{OH}$, and they produced 57.8 and $13.7 \mu \mathrm{mol} \mathrm{g}{ }^{-1} \mathrm{~h}^{-1}$, respectively, under visible light irradiation $(>400 \mathrm{~nm}){ }^{105}$

Tungsten-based materials. Among the first group of metal oxides, $\mathrm{WO}_{3}$ has the smallest bandgap energy of $2.7 \mathrm{eV}$ and as the edge of its conduction band is located at $0 \mathrm{Vvs}$. NHE at pH 7, it cannot reduce $\mathrm{CO}_{2} \cdot{ }^{\mathbf{4}, 106}$ However, Xie et al. found that when the architecture of the $\mathrm{WO}_{3}$ changed from quasi-cubic with an equal percentage of $\{002\},\{200\}$ and $\{020\}$ facets to rectangular sheet-like with dominant $\{002\}$ facets, it could induce $\mathrm{CO}_{2} \mathrm{PR}$ in

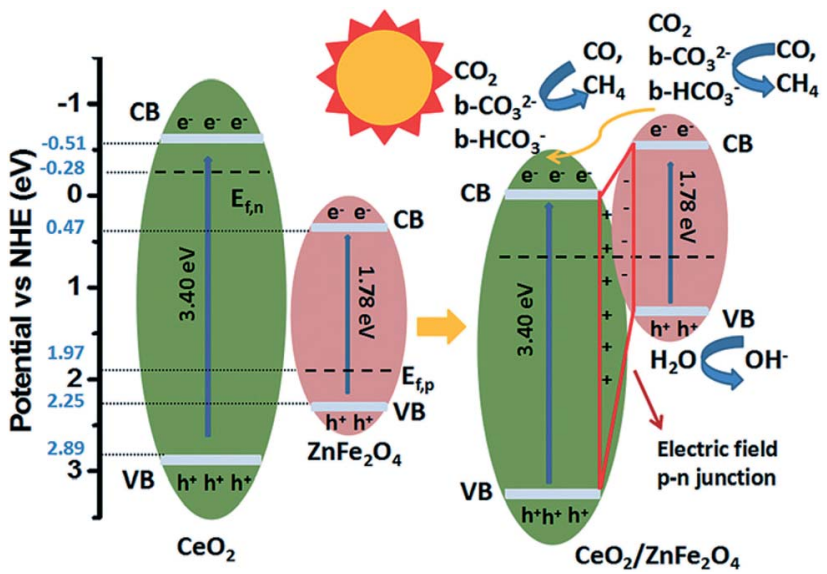

Fig. 7 Schematic of the mechanism of $\mathrm{CO}_{2}$ photoreduction with $\mathrm{H}_{2} \mathrm{O}$ vapour over $\mathrm{CeO}_{2} / \mathrm{ZnFe}_{2} \mathrm{O}_{4}$. Reproduced from ref. 82 with permission.

the presence of $\mathrm{H}_{2} \mathrm{O}^{83}$ The change of the predominantly exposed facets had a significant effect on the electronic configuration of $\mathrm{WO}_{3}$, in which the rectangular sheet-like $\mathrm{WO}_{3}$ possessed a slightly larger bandgap $(2.79 \mathrm{eV})$ and its conduction band was increased by $0.3 \mathrm{eV}$. As a result, the conduction band was positioned slightly above the $\mathrm{CH}_{4} / \mathrm{CO}_{2}$ potential $(-0.24 \mathrm{~V})$, inducing the methane formation from $\mathrm{CO}_{2}$ at a rate of $\sim 0.34$ $\mu \mathrm{mol} \mathrm{g}_{\text {catalyst }}{ }^{-1} \mathrm{~h}^{-1}$. Chen et al. found that the conduction band of $\mathrm{WO}_{3}$ was shifted to a more negative position $(-0.42 \mathrm{~V}$, bandgap energy: $2.79 \mathrm{eV}$ ) with a stronger reducing driving force, when the ultrathin $(\sim 4-5 \mathrm{~nm})$ single crystal $\mathrm{WO}_{3}$ was synthesized using a solid-liquid phase arc discharge route in an aqueous solution. ${ }^{84}$ The yield obtained from the $\mathrm{CO}_{2} \mathrm{PR}$ was $\sim 1.1 \mu \mathrm{mol} \mathrm{g}_{\text {catalyst }}{ }^{-1} \mathrm{~h}^{-1}$ under visible light irradiation $(\lambda>420$ $\mathrm{nm}$ ), whereas commercial $\mathrm{WO}_{3}$ powder produced only trace amounts of methane under the same conditions. A high aspect ratio of ultrathin $\mathrm{W}_{18} \mathrm{O}_{49}$ exhibited extended optical properties in the visible and near infrared regions due to the presence of a large amount of oxygen vacancies (Fig. 8). ${ }^{85}$ The synthesized
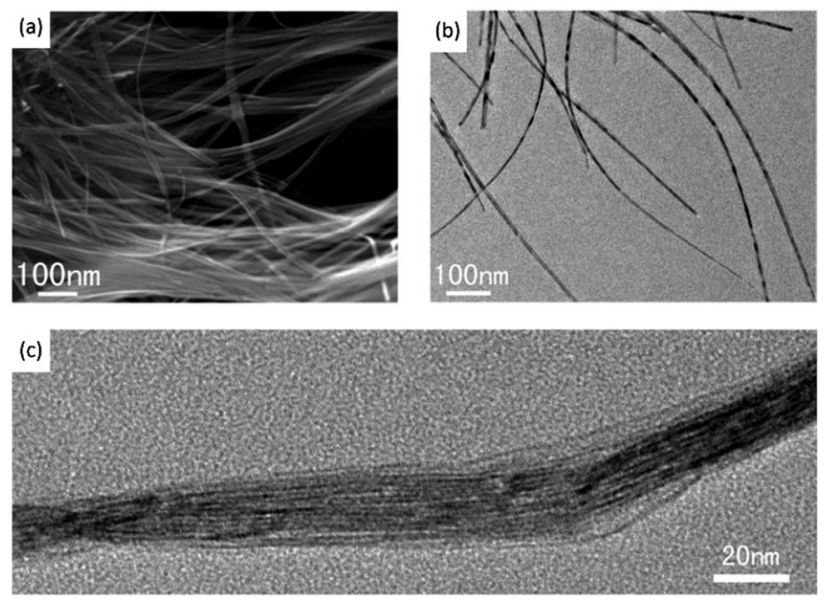

Fig. 8 SEM (a), TEM (b) and high resolution TEM (c) images of $\mathrm{W}_{18} \mathrm{O}_{49}$. Reproduced from ref. 85 with permission. 
ultrathin $\mathrm{W}_{18} \mathrm{O}_{49}$ exhibited the photoreduction of $\mathrm{CO}_{2}$ to $\mathrm{CH}_{4}$ at $70{ }^{\circ} \mathrm{C}$ under visible light irradiation without a co-catalyst (Fig. 8, Table 1 entry 20). The study observed that the selectivity towards $\mathrm{CH}_{4}$ over other hydrocarbons (e.g., ethanol and acetone) was as high as $95 \%$.

The introduction of foreign elements into tungsten oxide, which generated ternary $\mathrm{Bi}_{2} \mathrm{WO}_{6}$, was reported. ${ }^{86}$ The $\mathrm{Bi}_{2} \mathrm{WO}_{6}$ with predominant $\{001\}$ facets was proposed to be the most energetically favoured reactive surface for $\mathrm{CO}_{2}$ dissociation, resulting in $1.1 \mu \mathrm{mol} \mathrm{g}$ catalyst $^{-1} \mathrm{~h}^{-1}$ of methane under visible light irradiation $(\lambda>420 \mathrm{~nm})$, whereas the bulk $\mathrm{Bi}_{2} \mathrm{WO}_{6}$ prepared through a solid state reaction produced only trace amounts of methane. Cheng et al. also proposed that the microstructure of $\mathrm{Bi}_{2} \mathrm{WO}_{6}$ could enhance $\mathrm{CO}_{2}$ adsorption. ${ }^{87} \mathrm{~A}$ template-free anion exchange strategy was used to synthesize hollow microspheres of $\mathrm{Bi}_{2} \mathrm{WO}_{6}$ (Fig. 9a and b). The synthesized $\mathrm{Bi}_{2} \mathrm{WO}_{6}$ exhibited higher $\mathrm{CO}_{2}$ adsorption capacity when compared to $\mathrm{BiVO}_{4}$ and $\mathrm{BiPO}_{4}$ nanoparticles without hollow structures (Fig. 9c and d, respectively), leading to high photoconversion of $\mathrm{CO}_{2}$ into methanol.

Niobate-based materials. Niobates with a perovskite structure have gained some attention because they share many characteristics (i.e., non-toxicity, stability, and indirect wide bandgap) with titanates. Moreover, the conduction band of niobates is slightly more reductive than that of titanates, suggesting that niobates could be a more suitable material for $\mathrm{CO}_{2}$ PR. A study had shown that the microstructure of $\mathrm{NaNbO}_{3}$ played an important role in its photocatalytic activity. $\mathrm{NaNbO}_{3}$ nanowires (653 $\mathrm{ppm} \mathrm{h}^{-1} \mathrm{~g}^{-1}$, Fig. 10a) with a smaller bandgap $(3.2 \mathrm{eV})$ and larger surface area $\left(12.0 \mathrm{~m}^{2} \mathrm{~g}^{-1}\right)$ exhibited much higher methane formation from $\mathrm{CO}_{2}$ when compared to the $\mathrm{NaNbO}_{3}$ bulk $\left(3.2 \mathrm{eV}, 1.4 \mathrm{~m}^{2} \mathrm{~g}^{-1}, 22 \mathrm{ppm} \mathrm{h}^{-1} \mathrm{~g}^{-1}\right.$, Fig. 10b). ${ }^{88}$ The enhanced photocatalytic activity was proposed to be due to the high crystallinity, high aspect ratio and anisotropic effect of the synthesized nanowires. Li et al. also demonstrated that the size and microstructure of photocatalysts play an important role in their photocatalytic activity. ${ }^{89} \mathrm{KNb}_{3} \mathrm{O}_{8}$ and $\mathrm{HNb}_{3} \mathrm{O}_{8}$
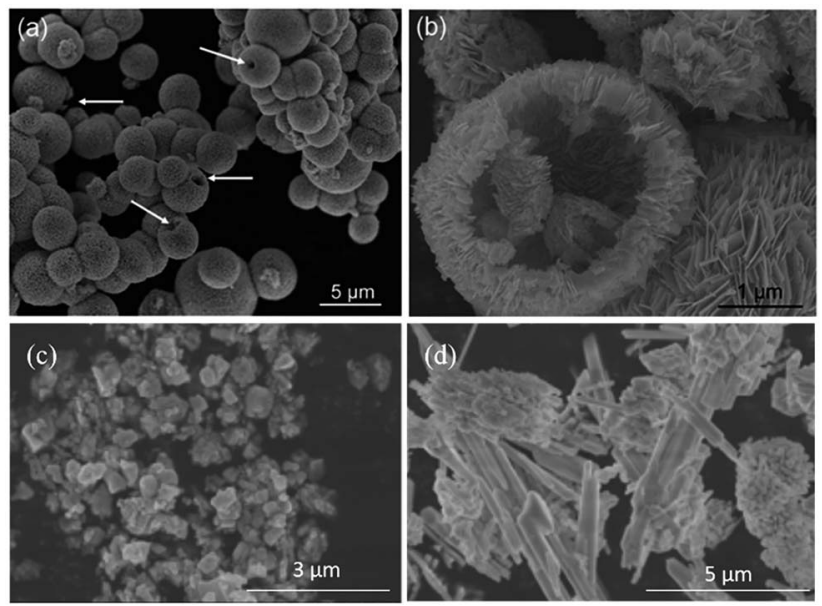

Fig. 9 SEM images of $\mathrm{Bi}_{2} \mathrm{WO}_{6}$ hollow microspheres (a and b), $\mathrm{BiVO}_{4}$ (c) and $\mathrm{BiPO}_{4}(\mathrm{~d})$ reproduced from ref. 87 with permission.
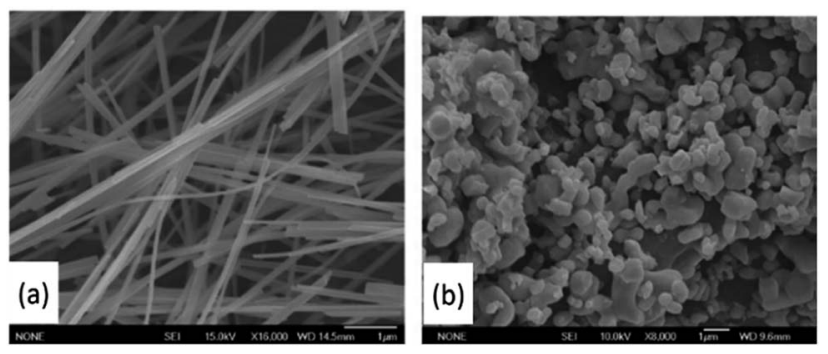

Fig. $10 \mathrm{NaNbO}_{3}$ nanowires (a) and bulk particles (b). Reproduced from ref. 88 with permission.

nanobelt samples with a higher surface area, which were 28.8 and $39.4 \mathrm{~m}^{2} \mathrm{~g}^{-1}$, respectively, exhibited $\mathrm{a} \geq 10$ times higher photoproduction rate of methane from $\mathrm{CO}_{2}$ than the irregularly shaped $\mathrm{KNb}_{3} \mathrm{O}_{8}$ and $\mathrm{HNb}_{3} \mathrm{O}_{8}$ samples, which were 2.7 and $6.5 \mathrm{~m}^{2} \mathrm{~g}^{-1}$, respectively (Table 1 entry 24 and 25). A similar observation was reported by Xie et al., in which the nanoplates of $\mathrm{SrNb}_{2} \mathrm{O}_{6}$ with an increased surface area revealed improved chemisorption of $\mathrm{CO}_{2}$ and the separation of photogenerated electron-hole pairs. ${ }^{107}$ As a result, more products, such as CO and $\mathrm{CH}_{4}$, were obtained from the $\mathrm{CO}_{2} \mathrm{PR}$ compared to the $\mathrm{SrNb}_{2} \mathrm{O}_{6}$ nanorods and nanoparticles with a lower surface area. A more recent study revealed that the nanorod-structured $\mathrm{SrNb}_{2} \mathrm{O}_{6}\left(1.78 \mathrm{~m}^{2} \mathrm{~g}^{-1}, 51.2 \mu \mathrm{mol} \mathrm{g}_{\text {catalyst }}{ }^{-1} \mathrm{~h}^{-1}\right)$ exhibited a higher photoreduction rate and selectivity towards $\mathrm{CO}$ evolution over $\mathrm{H}_{2}(>95 \%)$ than the $\mathrm{SrNb}_{2} \mathrm{O}_{7}$ nanoflakes $\left(3.85 \mathrm{~m}^{2} \mathrm{~g}^{-1}, 6\right.$ $\mu$ mol g $\mathrm{g}_{\text {catalyst }}{ }^{-1} \mathrm{~h}^{-1}, \sim 39 \%$ ) and $\mathrm{SrNb}_{2} \mathrm{O}_{6}$ nanoparticles even though the latter possessed a higher surface area. ${ }^{90}$ This phenomenon was attributed to the separation of the reduction and oxidation sites on the nanorods that decreased the recombination of photogenerated electron-hole pairs.

Tantalum-based materials. Tantalum-based semiconductors have been widely used as a photocatalyst for water splitting. Having higher potentials than $\mathrm{TiO}_{2}$ and above the reduction potential of $\mathrm{CO}_{2} / \mathrm{CH}_{3} \mathrm{OH}, \mathrm{H}_{2} \mathrm{CO}_{3} / \mathrm{CH}_{3} \mathrm{OH}, \mathrm{HCO}_{3}{ }^{-} / \mathrm{CH}_{3} \mathrm{OH}$ and $\mathrm{CO}_{3}{ }^{2-} / \mathrm{CH}_{3} \mathrm{OH}, \mathrm{Ta}_{2} \mathrm{O}_{5}$ can be employed for the $\mathrm{CO}_{2} \mathrm{PR}^{{ }^{92}}$ However, the large bandgap energy of $\mathrm{Ta}_{2} \mathrm{O}_{5}(\sim 3.9 \mathrm{eV})$ has restricted its light absorption in the visible region. ${ }^{108}$ Hence, Sato et al. used $\mathrm{N}-\mathrm{Ta}_{2} \mathrm{O}_{5}$ to couple a series of ruthenium bipyridine catalysts for the photocatalytic $\mathrm{CO}_{2}$ reduction to formic acid under visible light irradiation $(405 \mathrm{~nm}) .{ }^{109}$ The production rate was found to be $\sim 70 \mu \mathrm{mol} \mathrm{g}$ catalyst ${ }^{-1} \mathrm{~h}^{-1}$ in an acetonitrile/ triethanolamine mixture. To enhance the electron transportation and suppress the electron-hole recombination, $\mathrm{Ta}_{2} \mathrm{O}_{5}$ was immobilised on reduced graphene and $\mathrm{NiO}_{x}$ was used as the co-catalyst (Fig. 11). ${ }^{91}$ The highest photoproduction rate of methanol from $3 \% \mathrm{NiO}_{x}-\mathrm{Ta}_{2} \mathrm{O}_{5}-1 \%$ reduced graphene sample was $\sim 20.83$ and $197.92 \mu \mathrm{mol} \mathrm{g}$ catalyst ${ }^{-1} \mathrm{~h}^{-1}$ without and with the presence of $\mathrm{NaHCO}_{3}$ solution, respectively.

Much effort has focused on $\mathrm{InTaO}_{4}$ as the ternary tantalumbased semiconducting photocatalyst for $\mathrm{CO}_{2} \mathrm{PR}$. For instance, Pan and Chen demonstrated that $\mathrm{InTaO}_{4}$ could reduce $\mathrm{CO}_{2}$ to methanol $\left(\sim 1.1 \mu \mathrm{mol} \mathrm{g}\right.$ catalyst $\left.^{-1} \mathrm{~h}^{-1}\right)$ in $0.2 \mathrm{M} \mathrm{KHCO}_{3}$ aqueous solution under visible light irradiation. ${ }^{\mathbf{1 1 0}}$ The methanol production rate could marginally increase to $1.2 \mu \mathrm{mol} \mathrm{g}_{\text {catalyst }}{ }^{-1}$ 
$\mathrm{h}^{-1}$ after coupling $1 \mathrm{wt} \% \mathrm{NiO}$ as the co-catalyst and $1.4 \mu \mathrm{mol}$ $\mathrm{g}_{\text {catalyst }}{ }^{-1} \mathrm{~h}^{-1}$ after the application of reduction-oxidation pretreatment. Tuning the size and crystallinity of $\mathrm{InTaO}_{4}$ nanoparticles resulted in the bandgap energy range from 2.6 to $3.0 \mathrm{eV}$ and could also enhance the production of methanol from $\mathrm{CO}_{2} \cdot{ }^{111}$ The highest production rate was about $2.7 \mu \mathrm{mol}$ $\mathrm{g}_{\text {catalyst }}{ }^{-1} \mathrm{~h}^{-1}$ when $1.0 \mathrm{wt} \% \mathrm{NiO}$ was added as the co-catalyst. The methanol generation from $\mathrm{InTaO}_{4}$ was further enhanced by introducing core-shell $\mathrm{Ni} / \mathrm{NiO}$ nanoparticles on nitrogen doped $\mathrm{InTaO}_{4}$, leading to $160 \mu \mathrm{mol} \mathrm{g}$ catalyst ${ }^{-1} \mathrm{~h}^{-1}$ under the irradiation of light with wavelengths ranging from 390 to $770 \mathrm{~nm} .{ }^{92} \mathrm{KTaO}_{3}$ was also used to reduce $\mathrm{CO}_{2}$ to $\mathrm{CO}$ under visible light irradiation. ${ }^{\mathbf{1 1 2}}$ Three samples were synthesized with different bandgaps ranging from 3.5 to $3.7 \mathrm{eV}$ and yielded the highest amount of $\mathrm{CO}$ at $\sim 62 \mathrm{ppm} \mathrm{g}_{\text {catalyst }}{ }^{-1} \mathrm{~h}^{-1}$.

Recently, $\mathrm{LaTa}_{7} \mathrm{O}_{19}$ and $\mathrm{CaTa}_{4} \mathrm{O}_{11}$ (bandgap energies of 4.1 and $4.5 \mathrm{eV}$, respectively) were shown to be active for $\mathrm{CO}_{2} \mathrm{PR}$. CO was produced after loading with $1 \mathrm{wt} \% \mathrm{Ag}$ co-catalyst due to the preferable conduction band positions (50 and $70 \mu \mathrm{mol} \mathrm{g}_{\text {catalyst }}{ }^{-1}$ $\mathrm{h}^{-1}$, respectively, in the presence of $0.1 \mathrm{M} \mathrm{NaHCO}_{3}$ under the irradiation of a $400 \mathrm{~W}$ high-pressure mercury lamp). ${ }^{93} \mathrm{NaTaO}_{3}$ doped with different elements, such as $\mathrm{Mg}, \mathrm{Ca}, \mathrm{Sr}, \mathrm{Ba}$ and $\mathrm{La}$, has been proposed as a highly active photocatalyst for $\mathrm{CO}_{2} \mathrm{PR}$ using water as the electron donor in the presence of a $\mathrm{Ag}$ cocatalyst under UV irradiation. ${ }^{94}$ Among the samples, Ba-doped $\mathrm{NaTaO}_{3}$ loaded with $1.0 \mathrm{wt} \% \mathrm{Ag}$ co-catalyst using the liquidphase reduction method exhibited the highest CO production and selectivity from $\mathrm{CO}_{2}\left(\sim 50 \mu \mathrm{mol} \mathrm{g} \mathrm{g}_{\text {catalyst }}{ }^{-1} \mathrm{~h}^{-1}\right.$ and $56 \%$, respectively).

Quaternary tantalates have been developed recently and revealed to be active for $\mathrm{CO}_{2}$ photoreduction in the presence of water. ${ }^{113} \mathrm{~K}_{2} \mathrm{RETa}_{5} \mathrm{O}_{15}$ (RE = rare-earth element, namely La, Ce, $\mathrm{Pr}, \mathrm{Nd}, \mathrm{Y}$, and Sm) was fabricated using the flux method with $\mathrm{KCl}$, which favoured the rod-like morphology, followed by calcination treatment at $1150{ }^{\circ} \mathrm{C}$ for $6 \mathrm{~h} .{ }^{95}$ Among the quaternary tantalates, $\mathrm{K}_{2} \mathrm{CeTa}_{5} \mathrm{O}_{15}$ possessed the smallest bandgap energy $\left(2.42 \mathrm{eV}, 0.7 \mu \mathrm{mol} \mathrm{g}\right.$ catalyst $\left.^{-1} \mathrm{~h}^{-1}\right)$, but $\mathrm{K}_{2} \mathrm{YTa}_{5} \mathrm{O}_{15}$ photoproduced the highest amount of $\mathrm{CO}(3.86 \mathrm{eV}, 91.9 \mu \mathrm{mol}$ $\mathrm{g}_{\text {catalyst }}{ }^{-1} \mathrm{~h}^{-1}$ ). The addition of $\mathrm{Y}$ was shown to be beneficial for capturing $\mathrm{CO}_{2}$ and subsequently for photoreduction. Meanwhile, the presence of $\mathrm{K}$ in the tantalates played an important role in determining the growth orientation of the rod-like structure, thereby affecting the activity in $\mathrm{CO}_{2}$ photoreduction.

Miscellaneous. $\mathrm{CeO}_{2}$ is a basic metal oxide that can transform inert linear $\mathrm{CO}_{2}$ to $\mathrm{b}-\mathrm{HCO}_{3}{ }^{-}$and $\mathrm{b}-\mathrm{CO}_{3}{ }^{2-}$ to reduce the reductive potential of $\mathrm{CO}_{2} \cdot{ }^{114}$ Hence, it has recently attracted a lot of attention. However, it suffers from rapid recombination of photogenerated electron-hole pairs and possesses a large bandgap (3.0-3.4 eV), which restricts the light absorption in the UV range. ${ }^{115}$ To improve the performance of $\mathrm{CeO}_{2}$ for the photocatalytic reduction of $\mathrm{CO}_{2}$ under visible irradiation, Xiong et al. proposed the coupling of $\mathrm{Ag} / \mathrm{Ag}_{3} \mathrm{PO}_{4}$ with $\mathrm{CeO}_{2}$ to construct heterojunctions for enhancing the separation of photogenerated electron-hole pairs and improve light absorption because $\mathrm{Ag}_{3} \mathrm{PO}_{4}$ has a narrow bandgap of $2.42 \mathrm{eV} \cdot{ }^{116}$ The highest $\mathrm{CH}_{3} \mathrm{OH}$ and $\mathrm{C}_{2} \mathrm{H}_{5} \mathrm{OH}$ yield obtained was 10.6 and 7.9 $\mu \mathrm{mol} \mathrm{g}$ catalyst $^{-1} \mathrm{~h}^{-1}$, respectively. Zhang discovered that when Ni
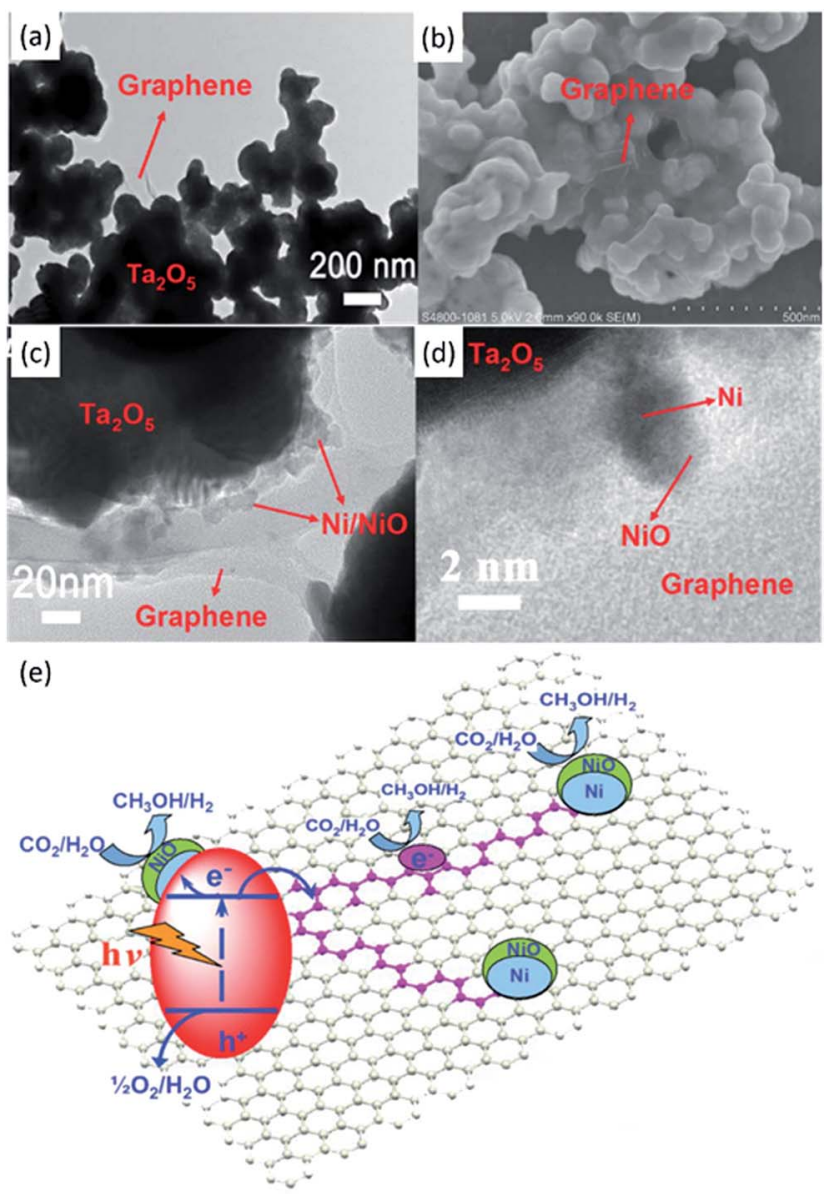

Fig. 11 TEM (a) and SEM (b) images of $\mathrm{Ta}_{2} \mathrm{O}_{5}$ immobilised on reduced graphene. TEM (c) and SEM (d) images of the $\mathrm{NiO}_{x}-\mathrm{Ta}_{2} \mathrm{O}_{5}$-reduced graphene composite. Schematic illustration of the charge separation and transfer in the $\mathrm{Ta}_{2} \mathrm{O}_{5}$-reduced graphene system under UV-vis light (e). Reproduced from ref. 91 with permission.

was loaded on $\mathrm{CeO}_{2}$, the nanocomposite exhibited enhanced photo(thermo)catalytic performance and inhibited carbon deposition. ${ }^{117}$ Moreover, it is interesting to note that the full light spectrum response from UV to infrared of the Ni metal on $\mathrm{CeO}_{2}$ decreased the activation energy of $\mathrm{C}$ and $\mathrm{CH}$ oxidation steps, thus improving the overall photo(thermo)catalytic performance.

$\mathrm{MgO}$ was employed to photocatalytically reduce $\mathrm{CO}_{2}$ into $\mathrm{CO}$ with a production rate of $\sim 1.6 \mu \mathrm{mol} \mathrm{g}{ }^{-1} \mathrm{~h}^{-1}$ over $6 \mathrm{~h}$ in the presence of $\mathrm{H}_{2}$ as the reductant under UV light $(\lambda<290 \mathrm{~nm}){ }^{118}$ Mesoporous $\mathrm{Ga}_{2} \mathrm{O}_{3}$ yielded 1.46 and $0.21 \mu \mathrm{mol} \mathrm{g}{ }^{-1} \mathrm{~h}^{-1}$ of $\mathrm{CO}$ and $\mathrm{CH}_{4}$, respectively, from $\mathrm{CO}_{2}$ under visible light irradiation. ${ }^{119}$ When $\mathrm{Ga}_{2} \mathrm{O}_{3}$ was loaded with $\mathrm{Ag}$, the photoproduction rate of $\mathrm{CO}$ from $\mathrm{CO}_{2}$ was $10.5 \mu \mathrm{mol} \mathrm{g}{ }^{-1} \mathrm{~h}^{-1}$ under UV light irradiation (Table 1 entry 33). ${ }^{96}$ Iron oxides were proposed as a photoactive centre to induce the photocatalytic reduction of $\mathrm{CO}_{2} \cdot{ }^{120}$ Using electron spin resonance spectroscopy (ESR), the photogenerated electrons from the $\mathrm{Fe}-\mathrm{O}$ species were efficiently consumed by $\mathrm{CO}_{2}$ under UV irradiation.

Lamellar $\mathrm{BiVO}_{4}$ was proposed to exhibit a selective methanol production from $\mathrm{CO}_{2}$ photoreduction under visible light 
irradiation. ${ }^{97}$ The maximum $\mathrm{CH}_{3} \mathrm{OH}$ production rate was 5.52 $\mu \mathrm{mol} \mathrm{h}{ }^{-1}$ when $0.2 \mathrm{~g}$ of $\mathrm{BiVO}_{4}$ was suspended in $100 \mathrm{~mL}$ of $\mathrm{NaOH}(1.0 \mathrm{M})$ under full spectrum irradiation of a Xe lamp. The photocatalytic mechanism was proposed according to which the $\mathrm{Bi}^{3+}$ sites could efficiently receive electrons from the $\mathrm{V}$ 3d-block bands of the $\mathrm{BiVO}_{4}$ to form $\mathrm{CO}_{2}{ }^{-}$radical anions, leading to the formation of methoxyl radicals $\left(\cdot \mathrm{OCH}_{3}\right)$ and eventually $\mathrm{CH}_{3} \mathrm{OH}$ after hydrogen abstraction. Wang et al. doped the atomically thin layers of $\mathrm{BiVO}_{4}$ with different percentages of Co. ${ }^{121}$ The Co-doped $\mathrm{BiVO}_{4}$ exhibited an efficient and stable activity for $\mathrm{CO}_{2}$ photoreduction to $\mathrm{CH}_{4}$. The optimal $\mathrm{CH}_{4}$ production rate was $23.8 \mu \mathrm{mol} \mathrm{g}^{-1} \mathrm{~h}^{-1}$, which was three times higher than that of the pristine $\mathrm{BiVO}_{4}$, at $60{ }^{\circ} \mathrm{C}$ with an atmospheric $\mathrm{CO}_{2}$ concentration $(\sim 400 \mathrm{ppm})$ under a UV lamp ( $25 \mathrm{~W}$ at $254 \mathrm{~nm}$ ). The enhancement of the production rate of the Co-doped $\mathrm{BiVO}_{4}$ was suggested to be due to the presence of electron enriched adsorption sites, which was contributed by the Co dopant, activating the $\mathrm{CO}_{2}$ molecules for further reduction reaction.

Delafossite materials with a general stoichiometry of $\mathrm{ABO}_{2}$, in which $\mathrm{A}$ is a monovalent metal ion, such as $\mathrm{Cu}, \mathrm{Ag}$, and $\mathrm{Pt}$, and $\mathrm{B}$ is a trivalent metal ion, such as $\mathrm{Al}, \mathrm{Ga}$, and $\mathrm{Fe}$, as the new class of photocatalysts have also been considered for $\mathrm{CO}_{2} \mathrm{PR}^{98}$ $\mathrm{CuGaO}_{2}$ (bandgap energy $\sim 3.7$ and weak absorption at $2.6 \mathrm{eV}$ ) and the Fe-alloyed $\mathrm{CuGa}_{1-x} \mathrm{Fe}_{x} \mathrm{O}(1.5 \mathrm{eV})$ facilitated the photogeneration of $\mathrm{CO}$ from $\mathrm{CO}_{2}$ under the irradiation of a Xe lamp though varied amounts of Fe substituted into $\mathrm{CuGaO}_{2}$ did not significantly enhance the $\mathrm{CO}_{2}$ photoreduction performance (Table 1 entry 35$)^{98}$

Based on the Lewis acidity of $\mathrm{CO}_{2}$, alkaline catalysts will benefit the adsorption and activation of $\mathrm{CO}_{2}$. Layered double hydroxide (LDH) materials usually possess high specific surface areas, which provide numerous active sites for the catalytic reaction. The fabricated CoAl $\mathrm{LDH}$ facilitated an enhanced $\mathrm{CO}_{2}$ photoreduction reaction when compared to P25 due to the surface alkaline $\mathrm{OH}$ groups for efficient adsorption of $\mathrm{CO}_{2}$ at a low concentration. ${ }^{99}$ The utilisation of $\mathrm{LDH}$ in $\mathrm{CO}_{2}$ photoreduction has been reviewed previously, and thus, interested readers may refer to the published review articles. ${ }^{\mathbf{4 0 , 1 2 2}}$

In summary, metal oxides have shown their ability to promote photocatalytic reduction of $\mathrm{CO}_{2}$, as discussed in the previous section. However, most of these photocatalysts only work under UV irradiation due to their large bandgap energies $(>3 \mathrm{eV})$. The relatively large bandgap of metal oxides originates from the valence band maximum, which is formed by $\mathrm{O} 2 \mathrm{p}$ orbitals and is more positive than $3 \mathrm{~V} \cdot{ }^{123}$ Hence, if metal oxides meet the thermodynamic requirement for $\mathrm{CO}_{2} \mathrm{PR}$ and $\mathrm{H}_{2} \mathrm{O}$ photooxidation, then the bandgap of the metal oxides inevitably becomes larger than $3.0 \mathrm{eV}$, which is too wide to absorb visible light. ${ }^{124}$

\subsection{Oxynitrides}

Tantalum-based materials. The $\mathrm{N} 2 \mathrm{p}$ orbital has a higher potential energy than the $\mathrm{O} 2 \mathrm{p}$ orbital, which indicates that metal oxynitrides as well as metal nitrides could be employed as an efficient photocatalyst. ${ }^{42,125}$ For example, in the case of tantalum oxynitride and tantalum nitride, when nitrogenbased $\mathrm{N} 2 \mathrm{p}$ atomic orbitals were introduced into $\mathrm{Ta}_{2} \mathrm{O}_{5}$, new orbitals with a higher bound state energy are generated, resulting in a decrease of bandgap energy..$^{42,108,126}$ As a result, the bandgaps of TaON and $\mathrm{Ta}_{3} \mathrm{~N}_{5}$ (2.5 and $2.1 \mathrm{eV}$, respectively) are both smaller than that of $\mathrm{Ta}_{2} \mathrm{O}_{5}(3.9 \mathrm{eV})$ and thus can effectively absorb visible light and drive the photocatalytic activity. Moreover, the $\mathrm{N}$ content plays an important role in determining the bandgap energy in oxynitrides and nitrides. Therefore, Gao et al. proposed a Ca-assisted urea synthesis method to controllably synthesise TaON and $\mathrm{Ta}_{3} \mathrm{~N}_{5}$ with a tailored $\mathrm{N}$ composition. ${ }^{127}$ In addition, the initial urea : Ta molar ratio used in the proposed synthesis method was also beneficial to control the size and homogeneity of the final product. Recently, the use of the porous spherical architecture of $\mathrm{TaON}$ for $\mathrm{CO}_{2}$ photoreduction was proposed. ${ }^{100}$ The surface area of the porous spherical TaON was $\sim 11.12 \mathrm{~m}^{2} \mathrm{~g}^{-1}$, whereas that of commercial TaON was $\sim 7.41 \mathrm{~m}^{2} \mathrm{~g}^{-1}$. As a result, the $\mathrm{CH}_{3} \mathrm{CHO}$ and $\mathrm{C}_{2} \mathrm{H}_{5} \mathrm{OH}$ production rates from $\mathrm{CO}_{2}$ using the porous TaON (0.52 and $2.03 \mu \mathrm{mol}$ $\mathrm{g}_{\text {catalyst }}{ }^{-1} \mathrm{~h}^{-1}$ ) were higher when compared to those of the commercial TaON $\left(0.16\right.$ and $\left.0.84 \mu \mathrm{mol} \mathrm{g}_{\text {catalyst }}{ }^{-1} \mathrm{~h}^{-1}\right)$ under visible light irradiation. The enhanced $\mathrm{CO}_{2} \mathrm{PR}$ in the porous $\mathrm{TaON}$ was attributed to the increase of surface area. In addition, the reduction of charge transfer distance and enhanced light scattering within the porous spherical structure were also suggested to play roles in enhancing the photocatalytic reduction of $\mathrm{CO}_{2}$.

The $\mathrm{CO}_{2} \mathrm{PR}$ is a multi-electron process, and a variety of products can be produced using a single semiconducting photocatalyst. The achievement of efficient and selective production of highly valuable fuels is critical for viable $\mathrm{CO}_{2}$ photoreduction processes. The application of perovskite oxynitrides, such as $\mathrm{CaTaO}_{2} \mathrm{~N}$ coupled with the binuclear $\mathrm{Ru}(\mathrm{II})$ complex photosensitiser and loaded with the Ag co-catalyst, revealed an enhanced selectivity for $\mathrm{HCOOH}$ production $(>99 \%)$ from $\mathrm{CO}_{2}$ under visible light irradiation due to the enhanced interfacial electron transfer. ${ }^{128}$ A similar approach with the same photosensitiser and co-catalyst coupled with yttrium-tantalum oxynitride (YTON) was recently proposed by the same group. ${ }^{129}$ The YTON $(2.1 \mathrm{eV})$ exhibited a smaller bandgap than $\mathrm{CaTaO}_{2} \mathrm{~N}(2.5 \mathrm{eV})$, thus extending the light absorption up to $600 \mathrm{~nm}$. Moreover, the selectivity for $\mathrm{HCOOH}$ formation from $\mathrm{CO}_{2}$ was not affected and remained as high as that in their previous study (>99\%).

Zinc-based materials. Mesoporous $\mathrm{ZnGeON}$ was used as a photocatalyst for $\mathrm{CO}_{2} \mathrm{PR}$ under visible light irradiation $(\lambda<$ $400 \mathrm{~nm}) .{ }^{130}$ The prolonged nitridation time from 1 to $15 \mathrm{~h}$ decreased the $\mathrm{Zn}$ and $\mathrm{O}$ contents, in which $\mathrm{Zn}$ was evaporated and $\mathrm{O}$ was substituted by $\mathrm{N}$, at $800{ }^{\circ} \mathrm{C}$ in an $\mathrm{NH}_{3}$ environment. However, the crystallinity of ZnGeON was enhanced with a slight decrease in the surface area. The $\mathrm{ZnGeO}$ nitrided for $10 \mathrm{~h}\left(24.4 \mathrm{~m}^{2} \mathrm{~g}^{-1}\right)$ exhibited the highest $\mathrm{CH}_{4}$ production rate of $2.7 \mathrm{ppm} \mathrm{g}_{\text {catalyst }}{ }^{-1} \mathrm{~h}^{-1}$, which was higher than those of the ZnGeON prepared using the solid-state reaction $\left(3.3 \mathrm{~m}^{2} \mathrm{~g}^{-1}\right.$, $\left.1.1 \mathrm{ppm} \mathrm{g}_{\text {catalyst }}{ }^{-1} \mathrm{~h}^{-1}\right)$ and $\mathrm{N}$-doped $\mathrm{TiO}_{2}(2.2 \mathrm{ppm}$ $\mathrm{g}_{\text {catalyst }}{ }^{-1} \mathrm{~h}^{-1}$ ). As discussed in Section 2.2, zinc-based materials like $\mathrm{ZnGa}_{2} \mathrm{O}_{4}$ possessed a bandgap energy of $\sim 4.5 \mathrm{eV}$, in which 
the valence band was mainly composed of $\mathrm{O} 2 \mathrm{p}$ and the conduction band was formed from the hybridization of $\mathrm{Ga} 4 \mathrm{~s}$ and Zn 4 p orbitals. ${ }^{\mathbf{8 0 1 0 1}}$ In order to reduce the bandgap energy, nitridation of mesoporous $\mathrm{ZnGa}_{2} \mathrm{O}_{4}$ was proposed. The nitridation of $\mathrm{ZnGa}_{2} \mathrm{O}_{4}$ stimulated the hybridization of $\mathrm{Zn} 3 \mathrm{~d}, \mathrm{~N} 2 \mathrm{p}$ and $\mathrm{O} 2 \mathrm{p}$ and formed the valence band, whereas the conduction band was composed of the Ga $4 \mathrm{~s}$ and 4 p orbitals. ${ }^{\mathbf{1 0 1}}$ As a result, the bandgap energy was reduced to $2.5 \mathrm{eV}$, resulting from the uplifting of the maximum of the valence band and lowering of the minimum of the conduction band. To further enhance the $\mathrm{CO}_{2} \mathrm{PR}$ performance, a $\mathrm{ZnGa}_{2} \mathrm{ON}$ solid solution was modified with $\mathrm{ZnAl}_{2} \mathrm{O}_{4}$ that acted as the $\mathrm{CO}_{2}$ arrester (Fig. 12). ${ }^{101}$ The increase of $\mathrm{Zn}$ content had also decreased the bandgap energy to $2.3 \mathrm{eV}$. Benefiting from the mesoporous structure, smaller bandgap and enhanced $\mathrm{CO}_{2}$ adsorption ability, the $\mathrm{ZnAl}_{2} \mathrm{O}_{4}$-modified $\mathrm{ZnGa}_{2} \mathrm{ON}$ showed a methane generation rate of $9.2 \mu \mathrm{mol} \mathrm{g}$ catalyst ${ }^{-1} \mathrm{~h}^{-1}$ from $\mathrm{CO}_{2}$, which was 9 times higher than that of the pristine $\mathrm{ZnGa}_{2} \mathrm{ON}$ under visible light irradiation $(\lambda \geq 420 \mathrm{~nm})$.

\subsection{Nitrides}

Gallium-based materials. Through engineering the nanostructure of the co-catalyst used, selectivity using semiconducting nitrides could be enhanced dramatically, as demonstrated by AlOtaibi et al. ${ }^{102}$ The decoration of the nonpolar GaN nanowires with the Rh core and amorphous $\mathrm{Cr}_{2} \mathrm{O}_{3}$ shell co-catalyst significantly increased the production rate of $\mathrm{CH}_{4}$ from 1.3 (bare $\mathrm{GaN}$ ) to $3.5 \mu \mathrm{mol} \mathrm{g}$ catalyst ${ }^{-1} \mathrm{~h}^{-1}$, but the $\mathrm{CO}$ production rate decreased from 1130 (bare GaN) to $\sim 120 \mu \mathrm{mol}$ $\mathrm{g}_{\text {catalyst }}{ }^{-1} \mathrm{~h}^{-1}$ in $24 \mathrm{~h}$ (Fig. 12). Due to the effective collection of photogenerated electrons by the Rh core and amorphous $\mathrm{Cr}_{2} \mathrm{O}_{3}$ shell co-catalyst, no apparent reductive reaction (e.g., photoreduction of $\mathrm{CO}_{2}$ to $\mathrm{CO}$ ) occurred on the surface of $\mathrm{GaN}$ without Rh coverage. As a result, the product selectivity towards $\mathrm{CH}_{4}$ was enhanced in the $\mathrm{CO}_{2} \mathrm{PR}$ under UV-visible light irradiation. In addition, the decoration of the GaN nanowires with $\mathrm{Rh} / \mathrm{Cr}_{2} \mathrm{O}_{3}$ could suppress the back reaction that formed $\mathrm{H}_{2} \mathrm{O}$ from $\mathrm{H}_{2}$ and $\mathrm{O}_{2}$, and offered adsorption sites for $\mathrm{CO}_{2}$.

In summary, both metal oxynitrides and nitrides have shown their capability to photoreduce $\mathrm{CO}_{2}$ with more favourable optical properties when compared to metal oxides. Unfortunately, these groups of materials have not been extensively explored.

(a)

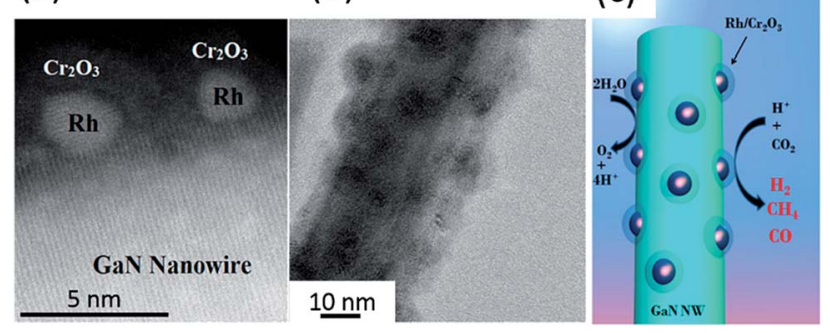

Fig. 12 (a) High-resolution TEM image and (b) TEM image of $\mathrm{Rh} / \mathrm{Cr}_{2} \mathrm{O}_{3}$ core/shell decorated GaN nanowires. (c) Schematic of the photoreduction processes of $\mathrm{CO}_{2}$ on $\mathrm{Rh} / \mathrm{Cr}_{2} \mathrm{O}_{3}$-decorated $\mathrm{GaN}$ nanowires. Reproduced from ref. 102 with permission.

\section{Hole scavengers for $\mathrm{CO}_{2}$ photoreduction}

Various semiconducting materials have been proposed as photocatalysts for $\mathrm{CO}_{2} \mathrm{PR}$ under UV and/or visible irradiation, as discussed in Section 2 and summarised in some other references. ${ }^{7-10,103,131}$ However, the quantum efficiency of the $\mathrm{CO}_{2}$ photo-conversion into hydrocarbons remained low and could not rely only on the development of photocatalysts. System optimisation plays an important role in optimising the conversion rate and selectivity as well as photocatalyst stability. Therefore, the increase of $\mathrm{CO}_{2} \mathrm{PR}$ efficiency through the introduction of a hole scavenging agent has gained significant interest. In this section, the use of organic and inorganic hole scavengers is reviewed.

\subsection{Inorganic hole scavengers}

As discussed in Section 2.1, metal sulphides suffer from photocorrosion in an aqueous dispersion due to the oxidation of lattice $\mathrm{S}^{2-}$ ions to elemental $\mathrm{S}$ and subsequently to sulphates. ${ }^{\mathbf{}}$ Hence, the addition of reducing agents to prevent the oxidation of the lattice $\mathrm{S}^{2-}$ ions by scavenging the photogenerated holes was proposed. Kanemoto et al. achieved a cumulative quantum yield of $72 \%$ with irradiation of UV light at $313 \mathrm{~nm}$ (i.e., 75.1 and $1.7 \mu \mathrm{mol} \mathrm{g}$ catalyst $^{-1} \mathrm{~h}^{-1}$ of $\mathrm{HCOOH}$ and $\mathrm{CO}$, respectively) when $\mathrm{NaH}_{2} \mathrm{PO}_{2}$ and $\mathrm{Na}_{2} \mathrm{~S}$ (0.35 and $0.24 \mathrm{M}$, respectively) were added into the system that contained $\mathrm{ZnS}$ as the photocatalyst for $\mathrm{CO}_{2} \mathrm{PR}$ (Table 2 entry 1 ). ${ }^{\mathbf{1 3 2}}$

A systematic study was recently carried out to investigate the effect of $\mathrm{Na}_{2} \mathrm{~S}$ as the hole scavenger for $\mathrm{ZnS}$ on the $\mathrm{CO}_{2} \mathrm{PR}$ at $\lambda=$ $345 \mathrm{~nm} .{ }^{133}$ The study elucidated that the photogenerated holes on the surface of $\mathrm{ZnS}$ were directly consumed by $\mathrm{Na}_{2} \mathrm{~S}$, whereas photogenerated electrons were pumped into the conduction band simultaneously. In addition, the behaviour of the reaction rate at different $\mathrm{pH}$ values resembled that of the solubility of $\mathrm{CO}_{2}$, discarding the direct participation of the $\mathrm{HCO}_{3}{ }^{-}$and $\mathrm{CO}_{3}{ }^{2-}$ in the photoreduction process. This observation was supported by a very recent study, in which $\mathrm{KHCO}_{3}$ was used as the hole scavenger in an aqueous system with $\mathrm{ZnS} .{ }^{\mathbf{1 3 4}}$ The study demonstrated that $\mathrm{KHCO}_{3}$ acted as an effective hole scavenger as well as a buffer to mitigate the $\mathrm{pH}$ change induced by the $\mathrm{CO}_{2}$ saturation. This phenomenon, however, was not observed when only $\mathrm{K}_{2} \mathrm{SO}_{3}$ was used as the hole scavenging agent.

The optimised solution with $0.1 \mathrm{~g}$ of colloidal $\mathrm{ZnS}, 0.1 \mathrm{M}$ $\mathrm{K}_{2} \mathrm{SO}_{3}$ and $0.5 \mathrm{M} \mathrm{KHCO}_{3}$ achieved 464.2 and $81.3 \mu \mathrm{mol}$ of $\mathrm{HCOOH}$ and $\mathrm{CO}$, respectively, under UV-vis irradiation (Table 2 entry 2). ${ }^{134}$ The selectivity towards $\mathrm{HCOOH}$ was reported to be $12.5 \%$, and this could be improved to $95.0 \%$ when $\mathrm{Cd}$ was added to the colloidal $\mathrm{ZnS}$ suspension as the co-catalyst.

Inorganic salts (e.g., $\mathrm{NaOH}, \mathrm{Na}_{2} \mathrm{~S}$, etc.) have been reported to have a significant effect on $\mathrm{CO}_{2} \mathrm{PR} \cdot{ }^{97,132,134,135}$ The addition of $\mathrm{NaOH}$ had been shown to increase the solubility of $\mathrm{CO}_{2}$ compared to pure $\mathrm{H}_{2} \mathrm{O}$ because the $\mathrm{OH}^{-}$ions provided by $\mathrm{NaOH}$ in aqueous solution reacted with the dissolved $\mathrm{CO}_{2}$, and transformed into $\mathrm{CO}_{3}{ }^{2-}$ and further into $\mathrm{HCO}_{3}{ }^{-}$in the $\mathrm{CO}_{2}$ saturated system. ${ }^{\mathbf{1 3 6}}$ It was suggested that the high 
Table 2 Photocatalytic $\mathrm{CO}_{2}$ reduction yields obtained by various photocatalyst after adding hole scavenger(s)

\begin{tabular}{|c|c|c|c|c|c|}
\hline No. & Photocatalyst & Hole scavenger & Function/role & $\begin{array}{l}\text { Product(s) of } \mathrm{CO}_{2} \\
\text { photoreduction } \\
\left(\mu \mathrm{mol}_{\text {catalyst }}{ }^{-1} \mathrm{~h}^{-1}\right)\end{array}$ & Ref. \\
\hline \multicolumn{6}{|c|}{ Inorganic } \\
\hline 1. & ZnS quantum crystallites & $\begin{array}{l}0.70 \mathrm{M} \mathrm{NaH}_{2} \mathrm{PO}_{2} \\
0.48 \mathrm{M} \mathrm{Na}_{2} \mathrm{~S}\end{array}$ & $\begin{array}{l}\text { Electron donor } \\
\text { Sulphur vacancy } \\
\text { suppressor }\end{array}$ & $\begin{array}{l}\text { HCOOH } 75.10 \\
\text { CO } 1.70\end{array}$ & 132 \\
\hline 2. & $\mathrm{ZnS}$ & $\begin{array}{l}0.1 \mathrm{M} \mathrm{K}_{2} \mathrm{SO}_{3} \\
0.1 \mathrm{M} \mathrm{K}_{2} \mathrm{SO}_{3}^{+} \\
0.5 \mathrm{M} \mathrm{KHCO}_{3}\end{array}$ & $\begin{array}{l}\text { Hole scavenger } \\
\text { Electron donor } \\
\text { Buffer solution }\end{array}$ & $\begin{array}{l}\mathrm{HCOOH} \sim 250.00 \\
\text { НCOOH } 580.30\end{array}$ & 134 \\
\hline 3. & $\mathrm{Zn}$-doped $\mathrm{Ga}_{2} \mathrm{O}_{3}$ & $0.1 \mathrm{M} \mathrm{NaHCO}_{3}$ & Hole scavenger & CO 117.00 & 138 \\
\hline $\begin{array}{l}4 . \\
5 .\end{array}$ & $\begin{array}{l}\text { Ag-loaded } \mathrm{SrNb}_{2} \mathrm{O}_{6} \\
\text { Ag-loaded } \mathrm{Sr}_{2} \mathrm{Nb}_{2} \mathrm{O}_{7}\end{array}$ & $0.1 \mathrm{M} \mathrm{NaHCO}_{3}$ & $\mathrm{CO}_{2}$ supply & $\begin{array}{l}\mathrm{CO} \sim 4.00 \\
\mathrm{CO} \sim 38.40\end{array}$ & 71 \\
\hline 6. & $\mathrm{Sr}$ and $\mathrm{Ag}$ co-loaded $\mathrm{NaTaO}_{3}$ & $0.1 \mathrm{M} \mathrm{NaHCO}_{3}$ & Buffer for supplying $\mathrm{CO}_{2}$ & $\mathrm{CO} \sim 352.00$ & 94 \\
\hline 7. & $\begin{array}{l}\text { Ni-Al layered double } \\
\text { hydroxides (LDHs) }\end{array}$ & $0.1 \mathrm{M} \mathrm{NaCl}$ & Hole scavenger & CO 112.80 & 139 \\
\hline 8. & $\mathrm{BiVO}_{4}$ & $1.0 \mathrm{M} \mathrm{NaOH}$ & Hole scavenger & $\mathrm{CH}_{3} \mathrm{OH} 5.52$ & 97 \\
\hline \multicolumn{6}{|c|}{ Organic } \\
\hline 9. & CdS & Acetonitrile + dichloromethane & Surface modifier & $\begin{array}{l}\left(\mathrm{CH}_{3}\right)_{2} \mathrm{CO} \sim 0.24 \mu \mathrm{mol} \text { with } \\
70 \mu \mathrm{M} \text { of } \mathrm{CdS} \text { powder }\end{array}$ & 140 \\
\hline & & $1.0 \mathrm{~mol} \mathrm{dm}^{-3} 2$-propanol & $\begin{array}{l}\text { Surface modifier } \\
\text { Hole scavenger }\end{array}$ & $\begin{array}{l}\left(\mathrm{CH}_{3}\right)_{2} \mathrm{CO} \sim 0.19 \mu \mathrm{mol} \text { with } \\
70 \mu \mathrm{M} \text { of } \mathrm{CdS} \text { powder }\end{array}$ & \\
\hline 10. & Wurtzite-ZnS & $\begin{array}{l}\text { Isopropanol } \\
\text { Ethylene glycol }\end{array}$ & $\begin{array}{l}\text { Hole scavenger } \\
\text { Hole scavenger }\end{array}$ & $\begin{array}{l}\mathrm{HCOOH} \sim 40 \mathrm{ppm} \mathrm{g}_{\text {catalyst }}{ }^{-1} \mathrm{~h}^{-1} \\
\mathrm{HCOOH} \sim 90 \mathrm{ppm} \mathrm{g}_{\text {catalyst }}^{-1} \mathrm{~h}^{-1}\end{array}$ & 141 \\
\hline 11. & $\begin{array}{l}\text { Mononuclear } \\
\mathrm{Ru} \text { complex } / \mathrm{C}_{3} \mathrm{~N}_{4}\end{array}$ & $\begin{array}{l}4: 1 \text { of } N, N \text {-dimethylacetamide } \\
\text { (DMA) : triethanolamine (TEOA) }\end{array}$ & $\begin{array}{l}\text { Proton quencher } \\
\text { Electron donor }\end{array}$ & $\mathrm{HCOOH} \sim 1100.00$ & 142 \\
\hline 12. & $\begin{array}{l}\text { Bi-nuclear Ru } \\
\text { complex/Ag-loaded } \mathrm{C}_{3} \mathrm{~N}_{4}\end{array}$ & $\begin{array}{l}4: 1 \text { of } N, N \text {-dimethylacetamide } \\
\text { (DMA) : triethanolamine (TEOA) }\end{array}$ & $\begin{array}{l}\text { Proton quencher } \\
\text { Electron donor }\end{array}$ & НCOOH $\sim 2115.00$ & 143 \\
\hline 13. & $\begin{array}{l}\text { Bi-nuclear Ru } \\
\text { complex/Ag-loaded } \mathrm{C}_{3} \mathrm{~N}_{4}\end{array}$ & $\begin{array}{l}1.0 \mathrm{mM} \text { ethylenediaminetetraacetic } \\
\text { acid disodium salt dihydrate, EDTA } \cdot \mathrm{Na}_{2}\end{array}$ & Electron donor & $\mathrm{HCOOH} \sim 31.67$ & 144 \\
\hline 14. & & $\begin{array}{l}1.0 \mathrm{mM} \text { ethylenediaminetetraacetic acid } \\
\text { disodium salt dihydrate }\left(\text { EDTA } \cdot \mathrm{Na}_{2}\right)+ \\
0.1 \mathrm{M} \mathrm{K}_{2} \mathrm{CO}_{3}\end{array}$ & $\begin{array}{l}\text { Electron donor } \\
\text { Surface modifier }\end{array}$ & $\mathrm{HCOOH} \sim 83.33$ & \\
\hline
\end{tabular}

concentration of $\mathrm{HCO}_{3}{ }^{-}$present in the system could accelerate the photoreduction reaction, thereby enhancing the photoreduction performance. ${ }^{136,137}$ The direct consumption of $\mathrm{HCO}_{3}{ }^{2-}$ to produce $\mathrm{CO}$ was observed in a $\mathrm{CO}_{2}$ aqueous solution using a Zn-doped $\mathrm{Ga}_{2} \mathrm{O}_{3}$ photocatalyst. ${ }^{138}$ This observation was further investigated by Nakanishi et al., in which the production of CO occurred after transforming $\mathrm{HCO}_{3}{ }^{-}$into $\mathrm{CO}_{2} \cdot{ }^{94}$ Therefore, the addition of $\mathrm{HCO}_{3}{ }^{-}$increased the $\mathrm{CO}_{2}$ supply in the aqueous system, but did not enhance the numbers of reacted electrons and holes. In other words, under basic conditions, $\mathrm{H}_{2}$ production could be significantly suppressed, resulting in a high selectivity of $\mathrm{CO}$ from $\mathrm{CO}_{2}$. Jin et al. concurred that the addition of $\mathrm{NaOH}$ promoted the formation of $\mathrm{HCO}_{3}{ }^{-}$; however, the production of methanol was observed in the photocatalytic system with a $\mathrm{BiVO}_{4}$ photocatalyst. ${ }^{97}$

The addition of $\mathrm{NaOH}, \mathrm{Na}_{2} \mathrm{CO}_{3}$ and $\mathrm{NaHCO}_{3}$ to the $\mathrm{CO}_{2}$ photoreduction aqueous solution was shown to promote the photoproduction of $\mathrm{CO}$, whereas $\mathrm{H}_{2} \mathrm{SO}_{4}$ and $\mathrm{NaCl}$ were found to favour water splitting, leading to the production of $\mathrm{H}_{2} \cdot{ }^{90,94,136,137}$ However, a recent study has proposed that the inclusion of $\mathrm{Cl}^{-}$ from $\mathrm{NaCl}$ could scavenge the photogenerated holes for the $\mathrm{CO}_{2}$ photocatalytic reduction process in a aqueous solution over $\mathrm{Ni}-$
Al layered double hydroxides. ${ }^{139}$ The selectivity towards CO over $\mathrm{H}_{2}$ was $86 \%$ when $\mathrm{NaCl}$ was added into the photoreduction system ( 6.95 and $\sim 1.16 \mu \mathrm{mol} \mathrm{g}^{-1} \mathrm{~h}^{-1}$ of $\mathrm{CO}$ and $\mathrm{H}_{2}$, respectively), whereas in the absence of a scavenging agent, the selectivity towards CO over $\mathrm{H}_{2}$ was only $54 \%$ ( $\sim 3.15$ and $\sim 2.63$ $\mu \mathrm{mol} \mathrm{g}{ }^{-1} \mathrm{~h}^{-1}$ of $\mathrm{CO}$ and $\mathrm{H}_{2}$, respectively). The authors also pointed out that the addition of $\mathrm{NaHCO}_{3}$ and $\mathrm{Na}_{2} \mathrm{CO}_{3}$ promoted the production of $\mathrm{H}_{2}$ via the reduction of $\mathrm{H}^{+}$derived from $\mathrm{H}_{2} \mathrm{O}$ instead of the $\mathrm{CO}_{2} \mathrm{PR}$. Neither $\mathrm{Na}_{2} \mathrm{SO}_{4}$ nor $\mathrm{NaNO}_{3}$ could positively enhance the production of $\mathrm{CO}$. A similar extent of $\mathrm{CO}$ evolution and selectivity were also observed when other chloride salts were added, namely $\mathrm{CsCl}\left(\sim 8 \mu \mathrm{mol} \mathrm{g}^{-1} \mathrm{~h}^{-1}\right.$ of $\mathrm{CO}$, $82 \%), \mathrm{MgCl}_{2}\left(\sim 7 \mu \mathrm{mol} \mathrm{g}^{-1} \mathrm{~h}^{-1}\right.$ of $\left.\mathrm{CO}, 82 \%\right)$ and $\mathrm{CaCl}_{2}(\sim 7.5$ $\mu \mathrm{mol} \mathrm{g}{ }^{-1} \mathrm{~h}^{-1}$ of $\left.\mathrm{CO}, 82 \%\right)$. However, other halogenide salts ( $\mathrm{NaBr}$ and $\mathrm{NaI}$ ) showed a weaker photoreduction ability than $\mathrm{NaCl}$.

\subsection{Organic hole scavengers}

Since the last century, ZnS had been used as photocatalyst for the $\mathrm{CO}_{2} \mathrm{PR}^{146,147}$ Triethylamine (TEA) showed its feasibility to be used as the hole scavenger, inhibiting the photocorrosion for sulphite photocatalysts. ${ }^{7}$ In $\mathrm{ZnS}$ systems, 2-propanol was one of 
the common hole scavengers for $\mathrm{CO}_{2} \mathrm{PR}$. A previous report proposed that the light energy could be stored within the lightinduced reaction given as

$$
\mathrm{CO}_{2}+\left(\mathrm{CH}_{3}\right)_{2} \mathrm{CHOH} \rightarrow \mathrm{HCOOH}+\left(\mathrm{CH}_{3}\right)_{2} \mathrm{CO}
$$

The Gibbs free energy of this reaction is $+62.8 \mathrm{~kJ} \mathrm{~mol}^{-1}$ at $25{ }^{\circ} \mathrm{C} .{ }^{147}$

In a system of Cd-loaded $\mathrm{ZnS}, \mathrm{CO}_{2}$ photoproduced formic acid with a quantum efficiency $32.5 \%$ in the presence of $1 \mathrm{M} 2$ propanol. ${ }^{147}$ Further increasing the Cd concentration resulted in the formation of $\mathrm{CO}$. A study revealed that $\mathrm{CdS}$ was capable of photoreducing $\mathrm{CO}_{2}$ to $\mathrm{CO}$ when $\mathrm{N}, \mathrm{N}$-dimethylformamide (DMF) containing $1 \mathrm{v} / \mathrm{v} \%$ water was employed in the system. ${ }^{148} \mathrm{~A}$ similar observation was reported, in which CO was photoproduced when CdS was dispersed in DMF under the irradiation of a $500 \mathrm{~W}$ mercury lamp with a $300 \mathrm{~nm}$ cut off filter. ${ }^{140}$ When DMF was substituted with a low polarity solvent, such as $\mathrm{CCl}_{4}$ and $\mathrm{CH}_{2} \mathrm{Cl}_{2}$, $\mathrm{CO}$ production was dominant, whereas when using a high polar solvent, such as $\mathrm{H}_{2} \mathrm{O}$, formate was produced. This was because the adsorbability of the $\mathrm{CO}_{2}{ }^{-}$, an intermediate species after the activation of $\mathrm{CO}_{2}$, was strongly dependent on the polarity of the solvent used. For instance, low polarity molecules enabled strong adsorption of $\mathrm{CO}_{2}{ }^{--}$on the Cd sites of CdS through the carbon atom of $\mathrm{CO}_{2}{ }^{-}$, which was not highly solvated in solvents of low polarity, resulting in the formation of CO. When high polar solvents were used, $\mathrm{CO}_{2}{ }^{-{ }^{-}}$was stabilised in the system and established only weak interactions with the photocatalyst. As a result, $\mathrm{CO}_{2}{ }^{\cdot-}$ tended to react with a proton and produced formate.

A recent study suggested that the $\mathrm{CO}_{2}$ photoreduction process can be greener when glycerol, which is a green solvent derived from vegetable oil, was used as the hole scavenger instead of petroleum-derived solvents. ${ }^{\mathbf{1 4 1}}$ In this study, wurtzite $\mathrm{ZnS}$ facilitated the photoproduction of formic acid from $\mathrm{CO}_{2}$ with an apparent quantum efficiency of $3.2 \%$ and $0.9 \%$ when glycerol and 2-propanol, respectively, were employed as the hole scavenger.

Cyclohexanol was used as the hole scavenger for the $\mathrm{CO}_{2}$ photoreduction under UV light irradiation. ${ }^{\mathbf{1 4 9}}$ The optimised sample exhibited the production of cyclohexyl formate and cyclohexanone (178.1 and $170.2 \mu \mathrm{mol} \mathrm{g}_{\text {catalyst }}{ }^{-1}$, respectively) after $8 \mathrm{~h}$. The authors elucidated that the production of cyclohexanone was slightly lower than that of cyclohexyl formate because some of the photogenerated holes were consumed by cyclohexanol to form cyclohexyl ether.

A recent study demonstrated that a $\mathrm{Ru}(\mathrm{II})$-complex $/ \mathrm{C}_{3} \mathrm{~N}_{4}$ nanocomposite could induce the photocatalytic $\mathrm{CO}_{2}$ reduction by using a mixture of solvents $(N, N$-dimethylacetamide and DMA/TEOA). ${ }^{142}$ The apparent quantum efficiency achieved was $5.7 \%$ at $400 \mathrm{~nm}$ (Table 2 Entry 12). In addition, the product selectivity of the $\mathrm{Ru}(\mathrm{II})$-complex/ $\mathrm{C}_{3} \mathrm{~N}_{4}$ nanocomposite could be enhanced through manipulating the solvent used (Fig. 13). ${ }^{\mathbf{1 4 5}}$

In order to avoid using organic solvents as the medium, the mononuclear $\mathrm{Ru}$ (II) complex proposed in a previous study ${ }^{\mathbf{1 4 2}}$ was replaced with a binuclear $\mathrm{Ru}(\mathrm{II})$ complex coupled with $\mathrm{Ag} / \mathrm{C}_{3} \mathrm{~N}_{4}$

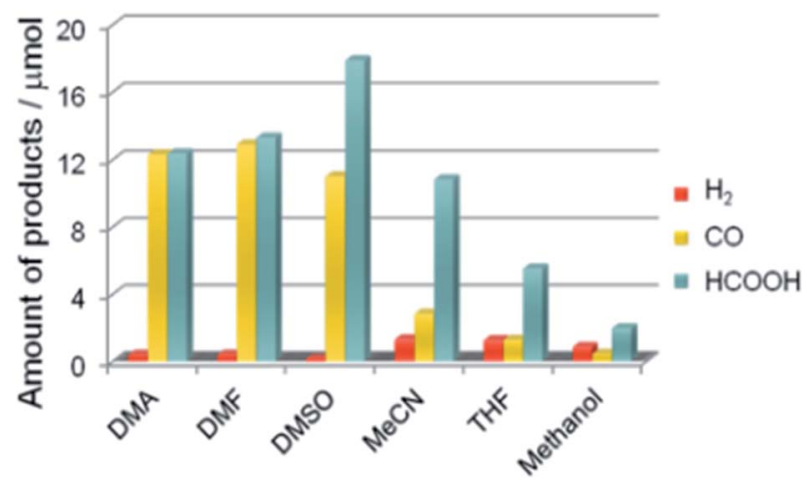

Fig. 13 Product distribution of visible light $(\lambda>400 \mathrm{~nm}) \mathrm{CO}_{2}$ reduction using $\mathrm{Ru}\left(\right.$ (I) complex $/ \mathrm{C}_{3} \mathrm{~N}_{4}$ as a photocatalyst and various solvents under a $\mathrm{CO}_{2}$ atmosphere (DMSO: dimethyl sulfoxide, MeCN: acetonitrile, and THF: tetrahydrofuran). Reproduced from ref. 145 with permission.

and was employed as the photocatalyst (Table 2 entry 13). ${ }^{\mathbf{1 4 3}}$ Since no reduction product was obtained in pure water, a hole scavenger (ethylenediaminetetraacetic acid disodium salt dihydrate, EDTA $\cdot \mathrm{Na}_{2}$ ) was added to promote the photocatalytic $\mathrm{CO}_{2}$ reduction in water. The main product was $\mathrm{HCOOH}$, and $\mathrm{H}_{2}$ was produced as a by-product under visible light irradiation $(\lambda>$ $400 \mathrm{~nm}$ ). Other hole scavenging agents (e.g., potassium oxalate and sodium ascorbate) were shown to be useful for the $\mathrm{CO}_{2} \mathrm{PR}$. Among the three hole scavenging agents, sodium ascorbate exhibited the best performance with $31.7 \mu \mathrm{mol}$ and $86 \%$ selectivity towards $\mathrm{HCOOH}$. The $\mathrm{HCOOH}$ production could be further enhanced to $83.3 \mu \mathrm{mol}$ with selectivity $97 \%$ when $\mathrm{K}_{2} \mathrm{CO}_{3}$ $(0.1 \mathrm{M})$ was used as an additive. ${ }^{\mathbf{1 4 4}}$ However, the production of $\mathrm{H}_{2}$ was reduced by half.

The introduction of organic and inorganic hole scavenging agents has exhibited advantages to enhance the efficiency of $\mathrm{CO}_{2} \mathrm{PR}$. The presence of hole scavenging agents in the $\mathrm{CO}_{2} \mathrm{PR}$ process is necessary if the oxidation reaction in the $\mathrm{CO}_{2} \mathrm{PR}$ cannot be inhibited by the photocatalyst. Moreover, to avoid carbon contamination and false positive errors for the photogeneration of hydrocarbons in the $\mathrm{CO}_{2} \mathrm{PR}$ process, inorganic hole scavenging agents are preferred.

\section{Conclusions and future directions}

To date, significant achievements have been made in the design and fabrication of photocatalysts and the optimisation of photocatalytic systems. $\mathrm{CO}_{2} \mathrm{PR}$ using metal sulphides, oxides, oxynitrides and nitrides accumulated so far have offered alternative photocatalytic materials other than $\mathrm{TiO}_{2}$. Material properties, including the surface area, light harvesting, and charge generation, separation and transportation, have been manipulated through the structural and morphological control during the fabrication processes, leading to enhanced $\mathrm{CO}_{2} \mathrm{PR}$ performance. Amongst the non-titania photocatalysts (metal sulphides, oxides, oxynitrides and nitrides) reviewed here, the ultrathin $\mathrm{W}_{18} \mathrm{O}_{49}$ exhibited the highest $\mathrm{CH}_{4}$ yield $(2200 \mu \mathrm{mol}$ $\mathrm{g}_{\text {catalyst }}{ }^{-1} \mathrm{~h}^{-1}$ ) from $\mathrm{CO}_{2}$ under visible light irradiation. The 
presence of oxygen vacancies was suggested to play an important role in the $\mathrm{CO}_{2} \mathrm{PR}$. On the other hand, the addition of inorganic salts or organic solvents into an aqueous system has shown to effectively scavenge the photogenerated holes and/or increase $\mathrm{CO}_{2}$ solubility.

Although significant studies have been carried out on $\mathrm{CO}_{2} \mathrm{PR}$, some challenges still remain. Firstly, an in-depth understanding of the working mechanism in a $\mathrm{CO}_{2}$ photoreduction process is still not well understood. Hence, a trial-anderror approach was used when fabricating photocatalysts, attempting to achieve a high $\mathrm{CO}_{2} \mathrm{PR}$ efficiency. Secondly, the insight into the $\mathrm{CO}_{2} \mathrm{PR}$ in the presence of hole scavenging agent(s) is not available. Moreover, due to this lack of knowledge, a rational design to combine state-of-art of photocatalysts with the desired hole scavenging agent(s) for carbon fuel production is difficult to achieve. Therefore, while more effort is required in material advancement, studies of the combined effect of the proposed photocatalyst with a hole scavenger should be encouraged. In addition, further investigation of $\mathrm{CO}_{2} \mathrm{PR}$ at the molecular level through in situ characterisation techniques should be carried out as this is key to boosting the efficiency of $\mathrm{CO}_{2} \mathrm{PR}$.

\section{Conflicts of interest}

There are no conflicts to declare.

\section{Acknowledgements}

The authors acknowledge the financial support provided by the Engineering and Physical Sciences Research Council (EP/ K021796/1), the Research Centre for Carbon Solutions (RCCS) and the Robert Buchan Chair in Sustainable Energy Engineering at Heriot-Watt University.

\section{References}

1 J. H. Montoya, L. C. Seitz, P. Chakthranont, A. Vojvodic, T. F. Jaramillo and J. K. Nørskov, Nat. Mater., 2016, 16, 70.

2 IEA Finds $\mathrm{CO}_{2}$ Emissions Flat for Third Straight Year Even as Global Economy Grew in 2016, https://www.iea.org/ newsroom/news/2017/march/iea-finds-co2-emissions-flatfor-third-straight-year-even-as-global-economy-grew.html.

3 Forecast of Worldwide Carbon Dioxide Emissions through 2040, https://www.statista.com/statistics/263980/forecastof-global-carbon-dioxide-emissions/.

4 T. Inoue, A. Fujishima, S. Konishi and K. Honda, Nature, 1979, 277, 637-638.

5 K. R. Thampi, J. Kiwi and M. Gratzel, Nature, 1987, 327, 506508.

6 Y. Y. Lee, H. S. Jung and Y. T. Kang, J. CO2 Util., 2017, 20, 163-177.

7 S. N. Habisreutinger, L. Schmidt-Mende and J. K. Stolarczyk, Angew. Chem., Int. Ed., 2013, 52, 7372-7408.

8 M. Marszewski, S. Cao, J. Yu and M. Jaroniec, Mater. Horiz., 2015, 2, 261-278.
9 K. Li, X. An, K. H. Park, M. Khraisheh and J. Tang, Catal. Today, 2014, 224, 3-12.

10 J. L. White, M. F. Baruch, J. E. Pander, Y. Hu, I. C. Fortmeyer, J. E. Park, T. Zhang, K. Liao, J. Gu, Y. Yan, T. W. Shaw, E. Abelev and A. B. Bocarsly, Chem. Rev., 2015, 115, 12888-12935.

11 Y. Yamazaki, H. Takeda and O. Ishitani, J. Photochem. Photobiol., C, 2015, 25, 106-137.

12 P. Salvador, J. Appl. Phys., 1984, 55, 2977-2985.

13 O. Carp, C. L. Huisman and A. Reller, Prog. Solid State Chem., 2004, 32, 33-177.

14 O. Ola and M. M. Maroto-Valer, J. Photochem. Photobiol., C, 2015, 24, 16-42.

15 M. S. Akple, J. Low, Z. Qin, S. Wageh, A. A. Al-Ghamdi, J. Yu and S. Liu, Chin. J. Catal., 2015, 36, 2127-2134.

16 K. Sasan, F. Zuo, Y. Wang and P. Feng, Nanoscale, 2015, 7, 13369-13372.

17 H. Zhao, L. Liu, J. M. Andino and Y. Li, J. Mater. Chem. A, 2013, 1, 8209-8216.

18 S.-M. Park, A. Razzaq, Y. H. Park, S. Sorcar, Y. Park, C. A. Grimes and S.-I. In, ACS Omega, 2016, 1, 868-875.

19 J. Xiao, D. Mao, X. Guo and J. Yu, Energy Technol., 2015, 3, 32-39.

20 G. Qin, Y. Zhang, X. Ke, X. Tong, Z. Sun, M. Liang and S. Xue, Appl. Catal., B, 2013, 129, 599-605.

21 E.-G. Ha, J.-A. Chang, S.-M. Byun, C. Pac, D.-M. Jang, J. Park and S. O. Kang, Chem. Commun., 2014, 50, 4462-4464.

22 Y. Liao, S.-W. Cao, Y. Yuan, Q. Gu, Z. Zhang and C. Xue, Chem. - Eur. J., 2014, 20, 10220-10222.

23 Q. Zhang, T. Gao, J. M. Andino and Y. Li, Appl. Catal., B, 2012, 123-124, 257-264.

24 J. Low, B. Cheng and J. Yu, Appl. Surf. Sci., 2017, 392, 658686.

25 P. Reñones, A. Moya, F. Fresno, L. Collado, J. J. Vilatela and V. A. de la Peña O'Shea, J. CO2 Util., 2016, 15, 24-31.

26 X. Chang, T. Wang and J. Gong, Energy Environ. Sci., 2016, 9, 2177-2196.

27 H. Tong, S. Ouyang, Y. Bi, N. Umezawa, M. Oshikiri and J. Ye, Adv. Mater., 2012, 24, 229-251.

28 Z. Zhu, Y. Han, C. Chen, Z. Ding, J. Long and Y. Hou, ChemCatChem, 2018, 10, 1627-1634.

29 J. Yu, J. Jin, B. Cheng and M. Jaroniec, J. Mater. Chem. A, 2014, 2, 3407-3416.

30 X. Li, J. Wen, J. Low, Y. Fang and J. Yu, Sci. China Mater., 2014, 57, 70-100.

31 J.-y. Tang, R.-t. Guo, W.-g. Zhou, C.-y. Huang and W.-g. Pan, Appl. Catal., B, 2018, 237, 802-810.

32 P. Xia, B. Zhu, J. Yu, S. Cao and M. Jaroniec, J. Mater. Chem. A, 2017, 5, 3230-3238.

33 W. Yu, D. Xu and T. Peng, J. Mater. Chem. A, 2015, 3, 1993619947.

34 M. Wang, J. Liu, C. Guo, X. Gao, C. Gong, Y. Wang, B. Liu, X. Li, G. G. Gurzadyan and L. Sun, J. Mater. Chem. A, 2018, 6, 4768-4775.

35 N. Nie, F. He, L. Zhang and B. Cheng, Appl. Surf. Sci., 2018, 457, 1096-1102. 
36 Y. Ma, Z. Wang, X. Xu and J. Wang, Chin. J. Catal., 2017, 38, 1956-1969.

37 H. Zhao, X. Yang, R. Xu, J. Li, S. Gao and R. Cao, J. Mater. Chem. A, 2018, 6, 20152-20160.

38 Y. Chen, D. Wang, X. Deng and Z. Li, Catal. Sci. Tech., 2017, 7, 4893-4904.

39 S. Ye, R. Wang, M.-Z. Wu and Y.-P. Yuan, Appl. Surf. Sci., 2015, 358, 15-27.

40 A. Nikokavoura and C. Trapalis, Appl. Surf. Sci., 2017, 391, 149-174.

41 X. Chen, S. Shen, L. Guo and S. S. Mao, Chem. Rev., 2010, 110, 6503-6570.

42 K. Maeda and K. Domen, J. Phys. Chem. C, 2007, 111, 78517861.

43 K. Maeda and K. Domen, J. Phys. Chem. Lett., 2010, 1, 26552661.

44 G. Liu, P. Niu, C. Sun, S. C. Smith, Z. Chen, G. Q. Lu and H.-M. Cheng, J. Am. Chem. Soc., 2010, 132, 11642-11648.

45 W.-N. Wang, W.-J. An, B. Ramalingam, S. Mukherjee, D. M. Niedzwiedzki, S. Gangopadhyay and P. Biswas, $J$. Am. Chem. Soc., 2012, 134, 11276-11281.

46 Y. Wei, J. Jiao, Z. Zhao, W. Zhong, J. Li, J. Liu, G. Jiang and A. Duan, J. Mater. Chem. A, 2015, 3, 11074-11085.

47 Z. Hu, M. Xu, Z. Shen and J. C. Yu,J. Mater. Chem. A, 2015, 3, 14046-14053.

48 F. R. F. Fan, P. Leempoel and A. J. Bard, J. Electrochem. Soc., 1983, 130, 1866-1875.

49 K. Kočí, L. Matějová, O. Kozák, L. Čapek, V. Valeš, M. Reli, P. Praus, K. Šafářová, A. Kotarba and L. Obalová, Appl. Catal., B, 2014, 158-159, 410-417.

50 P. Johne and H. Kisch, J. Photochem. Photobiol., A, 1997, 111, 223-228.

51 D. Meissner, R. Memming and B. Kastening, J. Phys. Chem., 1988, 92, 3476-3483.

52 X. Meng, G. Zuo, P. Zong, H. Pang, J. Ren, X. Zeng, S. Liu, Y. Shen, W. Zhou and J. Ye, Appl. Catal., B, 2018, 237, 68-73.

53 C. Yang, Q. Li, Y. Xia, K. Lv and M. Li, Appl. Surf. Sci., 2019, 464, 388-395.

54 Y. Chai, J. Lu, L. Li, D. Li, M. Li and J. Liang, Catal. Sci. Tech., 2018, 8, 2697-2706.

55 Z. Zhu, J. Qin, M. Jiang, Z. Ding and Y. Hou, Appl. Surf. Sci., 2017, 391, 572-579.

56 H. Kisch and P. Lutz, Photochem. Photobiol. Sci., 2002, 1, 240-245.

57 K. Kočí, P. Praus, M. Edelmannová, A. Nela, N. ová, I. Troppová, D. Fridrichová, G. owik and J. Ryczkowski, J. Nanosci. Nanotechnol., 2017, 17, 4041-4047.

58 P. Li, X. Zhang, C. Hou, L. Lin, Y. Chen and T. He, Phys. Chem. Chem. Phys., 2018, 20, 16985-16991.

59 X. Li, J. Chen, H. Li, J. Li, Y. Xu, Y. Liu and J. Zhou, J. Nat. Gas Chem., 2011, 20, 413-417.

60 P. Kar, S. Farsinezhad, X. Zhang and K. Shankar, Nanoscale, 2014, 6, 14305-14318.

61 J. Jin and T. He, Appl. Surf. Sci., 2017, 394, 364-370.

62 J. Jin, J. Yu, D. Guo, C. Cui and W. Ho, Small, 2015, 11, 52625271.
63 W. Li, D. Li, W. Zhang, Y. Hu, Y. He and X. Fu, J. Phys. Chem. C, 2010, 114, 2154-2159.

64 Q. Li, H. Meng, P. Zhou, Y. Zheng, J. Wang, J. Yu and J. Gong, ACS Catal., 2013, 3, 882-889.

65 Z. Han, G. Chen, C. Li, Y. Yu and Y. Zhou, J. Mater. Chem. A, 2015, 3, 1696-1702.

66 Y. Zhao, H. Pan, Y. Lou, X. Qiu, J. Zhu and C. Burda, J. Am. Chem. Soc., 2009, 131, 4253-4261.

67 W. Liang and M. H. Whangbo, Solid State Commun., 1993, 85, 405-408.

68 T. Arai, S. Tajima, S. Sato, K. Uemura, T. Morikawa and T. Kajino, Chem. Commun., 2011, 47, 12664-12666.

69 J.-Y. Liu, B. Garg and Y.-C. Ling, Green Chem., 2011, 13, 2029-2031.

70 A. Bachmeier, S. Hall, S. W. Ragsdale and F. A. Armstrong, J. Am. Chem. Soc., 2014, 136, 13518-13521.

71 A. Kubacka, M. Fernández-García and G. Colón, Chem. Rev., 2012, 112, 1555-1614.

72 H. W. Eng, P. W. Barnes, B. M. Auer and P. M. Woodward, J. Solid State Chem., 2003, 175, 94-109.

73 Z. Sheng, K. Piyush, T. Ujwal Kumar and S. Karthik, Nanotechnology, 2018, 29, 052001.

74 A. H. Yahaya, M. A. Gondal and A. Hameed, Chem. Phys. Lett., 2004, 400, 206-212.

75 J. Núñez, V. A. de la Peña O'Shea, P. Jana, J. M. Coronado and D. P. Serrano, Catal. Today, 2013, 209, 21-27.

76 L. Wan, X. Wang, S. Yan, H. Yu, Z. Li and Z. Zou, CrystEngComm, 2012, 14, 154-159.

77 Q. Liu, Y. Zhou, J. Kou, X. Chen, Z. Tian, J. Gao, S. Yan and Z. Zou, J. Am. Chem. Soc., 2010, 132, 14385-14387.

78 S. Yan, L. Wan, Z. Li and Z. Zou, Chem. Commun., 2011, 47, 5632-5634.

79 Q. Liu, Y. Zhou, Z. Tian, X. Chen, J. Gao and Z. Zou, J. Mater. Chem., 2012, 22, 2033-2038.

80 Q. Liu, D. Wu, Y. Zhou, H. Su, R. Wang, C. Zhang, S. Yan, M. Xiao and Z. Zou, ACS Appl. Mater. Interfaces, 2014, 6, 2356-2361.

81 Z. Li, Y. Zhou, J. Zhang, W. Tu, Q. Liu, T. Yu and Z. Zou, Cryst. Growth Des., 2012, 12, 1476-1481.

82 J. Guo, K. Wang and X. Wang, Catal. Sci. Tech., 2017, 7, 6013-6025.

83 Y. P. Xie, G. Liu, L. Yin and H.-M. Cheng, J. Mater. Chem., 2012, 22, 6746-6751.

84 X. Chen, Y. Zhou, Q. Liu, Z. Li, J. Liu and Z. Zou, ACS Appl. Mater. Interfaces, 2012, 4, 3372-3377.

85 G. Xi, S. Ouyang, P. Li, J. Ye, Q. Ma, N. Su, H. Bai and C. Wang, Angew. Chem., Int. Ed., 2012, 51, 2395-2399.

86 Y. Zhou, Z. Tian, Z. Zhao, Q. Liu, J. Kou, X. Chen, J. Gao, S. Yan and Z. Zou, ACS Appl. Mater. Interfaces, 2011, 3, 3594-3601.

87 H. Cheng, B. Huang, Y. Liu, Z. Wang, X. Qin, X. Zhang and Y. Dai, Chem. Commun., 2012, 48, 9729-9731.

88 H. Shi, T. Wang, J. Chen, C. Zhu, J. Ye and Z. Zou, Catal. Lett., 2011, 141, 525-530.

89 X. Li, H. Pan, W. Li and Z. Zhuang, Appl. Catal., A, 2012, 413-414, 103-108. 
90 R. Pang, K. Teramura, H. Asakura, S. Hosokawa and T. Tanaka, Appl. Catal., B, 2017, 218, 770-778.

91 X.-J. Lv, W.-F. Fu, C.-Y. Hu, Y. Chen and W.-B. Zhou, RSC Adv., 2013, 3, 1753-1757.

92 C.-W. Tsai, H. M. Chen, R.-S. Liu, K. Asakura and T.-S. Chan, J. Phys. Chem. C, 2011, 115, 10180-10186.

93 T. Takayama, H. Nakanishi, M. Matsui, A. Iwase and A. Kudo, J. Photochem. Photobiol., A, 2017, 358, 416-421.

94 H. Nakanishi, K. Iizuka, T. Takayama, A. Iwase and A. Kudo, ChemSusChem, 2017, 10, 112-118.

95 Z. Huang, K. Teramura, H. Asakura, S. Hosokawa and T. Tanaka, Catal. Today, 2018, 300, 173-182.

96 M. Yamamoto, T. Yoshida, N. Yamamoto, H. Yoshida and S. Yagi, e-J. Surf. Sci. Nanotechnol., 2014, 12, 299-303.

97 J. Mao, T. Peng, X. Zhang, K. Li and L. Zan, Catal. Commun., 2012, 28, 38-41.

98 J. W. Lekse, M. K. Underwood, J. P. Lewis and C. Matranga, J. Phys. Chem. C, 2012, 116, 1865-1872.

99 K. Wang, L. Zhang, Y. Su, D. Shao, S. Zeng and W. Wang, J. Mater. Chem. A, 2018, 6, 8366-8373.

100 Q. Han, Y. Zhou, L. Tang, P. Li, W. Tu, L. Li, H. Li and Z. Zou, RSC Adv., 2016, 6, 90792-90796.

101 S. Yan, H. Yu, N. Wang, Z. Li and Z. Zou, Chem. Commun., 2012, 48, 1048-1050.

102 B. AlOtaibi, S. Fan, D. Wang, J. Ye and Z. Mi, ACS Catal., 2015, 5, 5342-5348.

103 T.-M. Su, Z.-z. Qin, H.-B. Ji, Y.-x. Jiang and G. Huang, Environ. Chem. Lett., 2016, 14, 99-112.

104 G. Mahmodi, S. Sharifnia, F. Rahimpour and S. N. Hosseini, Sol. Energy Mater. Sol. Cells, 2013, 111, 3140.

105 J. Xiao, W. Yang, S. Gao, C. Sun and Q. Li, J. Mater. Sci. Technol., 2018, 34, 2331-2336.

106 G. R. Bamwenda and H. Arakawa, Appl. Catal., A, 2001, 210, 181-191.

107 S. Xie, Y. Wang, Q. Zhang, W. Deng and Y. Wang, Chem. Commun., 2015, 51, 3430-3433.

108 W.-J. Chun, A. Ishikawa, H. Fujisawa, T. Takata, J. N. Kondo, M. Hara, M. Kawai, Y. Matsumoto and K. Domen, J. Phys. Chem. B, 2003, 107, 1798-1803.

109 S. Sato, T. Morikawa, S. Saeki, T. Kajino and T. Motohiro, Angew. Chem., Int. Ed., 2010, 49, 5101-5105.

110 P.-W. Pan and Y.-W. Chen, Catal. Commun., 2007, 8, 15461549.

111 H.-C. Chen, H.-C. Chou, J. C. S. Wu and H.-Y. Lin, J. Mater. Res., 2011, 23, 1364-1370.

112 K. Li, A. D. M. Handoko, M. Khraisheh and J. Tang, Nanoscale, 2014, 6, 9767-9773.

113 Z. Huang, K. Teramura, S. Hosokawa and T. Tanaka, Appl. Catal., B, 2016, 199, 272-281.

114 L. Chen, D. Meng, X. Wu, A. Wang, J. Wang, Y. Wang and M. Yu, J. Phys. Chem. C, 2016, 120, 18548-18559.

115 X.-J. Wen, C.-G. Niu, L. Zhang, C. Liang and G.-M. Zeng, Appl. Catal., B, 2018, 221, 701-714.

116 W. Xiong, W. Dai, X. Hu, L. Yang, T. Wang, Y. Qin, X. Luo and J. Zou, Mater. Lett., 2018, 232, 36-39.
117 Q. Zhang, M. Mao, Y. Li, Y. Yang, H. Huang, Z. Jiang, Q. $\mathrm{Hu}, \mathrm{S} . \mathrm{Wu}$ and X. Zhao, Appl. Catal., B, 2018, 239, 555-564.

118 Y. Kohno, H. Ishikawa, T. Tanaka, T. Funabiki and S. Yoshida, Phys. Chem. Chem. Phys., 2001, 3, 11081113.

119 H.-a. Park, J. H. Choi, K. M. Choi, D. K. Lee and J. K. Kang, J. Mater. Chem., 2012, 22, 5304-5307.

120 Y. Tong, Y. Zhang, N. Tong, Z. Zhang, Y. Wang, X. Zhang, S. Zhu, F. Li and X. Wang, Catal. Sci. Tech., 2016, 6, 75797585.

121 K. Wang, L. Zhang, Y. Su, S. Sun, Q. Wang, H. Wang and W. Wang, Catal. Sci. Tech., 2018, 8, 3115-3122.

122 Y. Chen, G. Jia, Y. Hu, G. Fan, Y. H. Tsang, Z. Li and Z. Zou, Sustainable Energy Fuels, 2017, 1, 1875-1898.

123 D. E. Scaife, Sol. Energy, 1980, 25, 41-54.

124 K. Maeda, Prog. Solid State Chem., 2018, 51, 52-62.

125 K. Maeda, Phys. Chem. Chem. Phys., 2013, 15, 10537-10548.

126 M. Hara, G. Hitoki, T. Takata, J. N. Kondo, H. Kobayashi and K. Domen, Catal. Today, 2003, 78, 555-560.

127 Q. Gao, C. Giordano and M. Antonietti, Small, 2011, 7, 3334-3340.

128 F. Yoshitomi, K. Sekizawa, K. Maeda and O. Ishitani, ACS Appl. Mater. Interfaces, 2015, 7, 13092-13097.

129 K. Muraoka, H. Kumagai, M. Eguchi, O. Ishitani and K. Maeda, Chem. Commun., 2016, 52, 7886-7889.

130 N. Zhang, S. Ouyang, T. Kako and J. Ye, Chem. Commun., 2012, 48, 1269-1271.

131 H. L. Tuller, Mater. Renewable Sustainable Energy, 2017, 6, 3.

132 M. Kanemoto, T. Shiragami, C. Pac and S. Yanagida, J. Phys. Chem., 1992, 96, 3521-3526.

133 R. Zhou and M. I. Guzman, J. Phys. Chem. C, 2014, 118, 11649-11656.

134 X. Meng, Q. Yu, G. Liu, L. Shi, G. Zhao, H. Liu, P. Li, K. Chang, T. Kako and J. Ye, Nano Energy, 2017, 34, 524532.

135 S. Kaneco, Y. Shimizu, K. Ohta and T. Mizuno, J. Photochem. Photobiol., A, 1998, 115, 223-226.

136 I. H. Tseng, W.-C. Chang and J. C. S. Wu, Appl. Catal., B, 2002, 37, 37-48.

137 S. Liu, Z. Zhao and Z. Wang, Photochem. Photobiol. Sci., 2007, 6, 695-700.

138 K. Teramura, Z. Wang, S. Hosokawa, Y. Sakata and T. Tanaka, Chem. Eur. J., 2014, 20, 9906-9909.

139 S. Iguchi, K. Teramura, S. Hosokawa and T. Tanaka, Phys. Chem. Chem. Phys., 2015, 17, 17995-18003.

140 B.-J. Liu, T. Torimoto and H. Yoneyama, J. Photochem. Photobiol., A, 1998, 113, 93-97.

141 D. P. Leonard, H. Pan and M. D. Heagy, ACS Appl. Mater. Interfaces, 2016, 8, 1553.

142 R. Kuriki, K. Sekizawa, O. Ishitani and K. Maeda, Angew. Chem., Int. Ed., 2015, 54, 2406-2409.

143 R. Kuriki, H. Matsunaga, T. Nakashima, K. Wada, A. Yamakata, O. Ishitani and K. Maeda, J. Am. Chem. Soc., 2016, 138, 5159-5170. 
144 R. Kuriki, M. Yamamoto, K. Higuchi, Y. Yamamoto, M. Akatsuka, D. Lu, S. Yagi, T. Yoshida, O. Ishitani and K. Maeda, Angew. Chem., Int. Ed., 2017, 56, 4867-4871.

145 R. Kuriki, O. Ishitani and K. Maeda, ACS Appl. Mater. Interfaces, 2016, 8, 6011-6018.

146 I. Hiroshi, T. Tsukasa, S. Takao, M. Hirotaro and Y. Hiroshi, Chem. Lett., 1990, 19, 1483-1486.
147 H. Inoue, H. Moriwaki, K. Maeda and H. Yoneyama, J. Photochem. Photobiol., A, 1995, 86, 191-196.

148 K. Masashi, I. Ken-ichi, W. Yuji, S. Takao, M. Hirotaro and Y. Shozo, Chem. Lett., 1992, 21, 835-836.

149 G. Song, F. Xin and X. Yin, J. Colloid Interface Sci., 2015, 442, 60-66. 